TITLE:

\title{
Enhanced angiogenesis by multiple release of platelet-rich plasma contents and basic fibroblast growth factor from gelatin hydrogels.
}

\author{
$\operatorname{AUTHOR}(\mathrm{S}):$
}

Matsui, Makoto; Tabata, Yasuhiko

\section{CITATION:}

Matsui, Makoto ... [et al]. Enhanced angiogenesis by multiple release of platelet-rich plasma contents and basic fibroblast growth factor from gelatin hydrogels.. Acta biomaterialia 2012, 8(5): 1792-1801

\section{ISSUE DATE:}

2012-05

URL:

http://hdl.handle.net/2433/155091

\section{RIGHT:}

(c) 2012 Acta Materialia Inc. Published by Elsevier Ltd.; This is not the published version. Please cite only the published version.; この論文は 出版社版でありません。引用の際には出版社版をご確認ご利用くださ い。 
Title

Enhanced angiogenesis by multiple release of platelet-rich plasma contents and basic fibroblast growth

factor from gelatin hydrogels

Makoto Matsui, and Yasuhiko Tabata

Department of Biomaterials, Field of Tissue Engineering, Institute for Frontier Medical Sciences, Kyoto

University, 53 Kawahara-cho Shogoin, Sakyo-ku, Kyoto 606-8507, Japan

\section{Corresponding author}

Yasuhiko Tabata

Telephone number; +81-75-751-4121

Fax number; +81-75-751-4646

E-mail address; yasuhiko@frontier.kyoto-u.ac.jp 


\section{Abstract}

The objective of this study is to evaluate angiogenic effects induced by biodegradable gelatin hydrogel

granules incorporating mixed platelet-rich plasma (PRP) growth factor mixture (PGFM) and bFGF. The

PRP was prepared by a double-spinning technique of animal bloods isolated, followed by the treatment

with different concentrations of calcium chloride $\left(\mathrm{CaCl}_{2}\right)$ solution. The $\mathrm{CaCl}_{2}$ solution treatment activated

the platelets of PRP to allow releasing various growth factors, such as platelet-derived growth factor

(PDGF)-BB, vascular endothelial growth factor (VEGF), transforming growth factor (TGF)- $\beta_{1}$, and

epithelial growth factor (EGF). When determined in the PRP treated by different $\mathrm{CaCl}_{2}$ solutions, the high amount of representative platelet growth factor, PDGF-BB, VEGF, EGF, and TGF- $\beta_{1}$ were detected in the $\mathrm{CaCl}_{2}$ concentrations of 1,2 , and $4 \mathrm{wt} \%$ compared with higher or lower ones. The PRP treated was impregnated into gelatin hydrogels granules freeze-dried at $37^{\circ} \mathrm{C}$ for $1 \mathrm{hr}$, and then the percentage of PGFM desorbed from the gelatin hydrogel granules was evaluated. The percent PDGF-BB, VEGF, EGF, and TGF- $\beta_{1}$ desorbed tended to decrease with the decreased $\mathrm{CaCl}_{2}$ concentration. Taken together, the $\mathrm{CaCl}_{2}$ concentration to activate PRP for PGFM release was fixed at $2 \mathrm{wt} \%$. In vitro release tests demonstrated that the PGFM was released from the gelatin hydrogels granules with time. For the gelatin hydrogels incorporating PGFM and bFGF, the time profile of PDGF-BB or bFGF release was in good 
correspondence with that of gelatin hydrogel degradation. The gelatin hydrogels granules incorporating mixed PGFM and bFGF were prepared and intramuscularly injected to a leg ischemia model of mice to evaluate the angiogenic effects in terms of histological and laser Doppler perfusion imaging (LDPI) examinations. As controls, the hydrogel granules incorporating bFGF, PGFM, and platelet-poor plasma (PPP) were used for the angiogenic evaluation. The number of blood vessels newly formed and the percentage of $\alpha$-SMA-positive cells increased around ischemic sites injected with the gelatin hydrogel granules incorporating mixed PGFM and bFGF, in marked contrast to other control groups. The blood re-perfusion level of ischemic tissues was enhanced by the hydrogel granules incorporating mixed PGFM and bFGF, whereas no enhancement was observed for other groups. It is concluded that the dual release system of PGFM and bFGF from gelatin hydrogel granules is promising to enhance angiogenic effects.

\section{Keywords}

Gelatin hydrogel, PRP, bFGF, Controlled release, Angiogenesis 


\section{Introduction}

Several treatments for therapeutic angiogenesis have been reported to demonstrate their

potentials experimentally and clinically. Some clinical trials of gene therapy and bone marrow cells

transplantation have been being carried out. On the other hand, the biosafety of genetic materials is not always confirmed [1-3]. In addition, the invasiveness to harvest bone marrow cells and the insufficient scientific knowledge and the related technology for bone marrow cells may be potential risks for cell therapy $[4,5]$. Another choice is to make use of growth factor proteins, which enable cells to naturally induce their biological potentials for natural angiogenesis. If the growth factor can be used in vivo with the biological activity remaining, the growth factor-induced angiogenesis will be realistic.

Drug delivery system (DDS) is one of the practically possible technologies to positively modify the in vivo biological activity of growth factors. Biodegradable gelatin hydrogels have been designed and prepared for the controlled release of bioactive basic fibroblast growth factor (bFGF) [6], transforming growth factor (TGF)- $\beta_{1}$ [7], platelet-derived growth factor (PDGF)-BB [8], bone morphogenetic protein (BMP)-2 [9-11], and hepatocyte growth factor (HGF) [12, 13]. For example, bFGF could be released from the gelatin hydrogels to demonstrate the therapeutic potential of angiogenesis in the animal models of ischemic legs and hearts or the angiogenesis-induced enhancement 
of therapeutic efficacy of cell transplantation of cells [14-21]. In addition, a clinical trial has been started to confirm the safety and feasibility of bFGF release from gelatin hydrogels for patients with clinical limb ischemia of intractable disease [22].

Platelet-rich plasma (PRP) is a source of autologous growth factors, including PDGF, vascular endothelial growth factor (VEGF), TGF- $\beta_{1}$, and epithelial growth factor (EGF). Autologous PRP has been clinically used in a wide variety of surgical treatments for soft and hard tissues [23], such as the intractable wound [24], calvaria [25], or maxillofacial bone defects [26], cosmetic surgery [27, 28], spine literature [29], and neovascularization [30]. The platelet growth factors could be also released from the gelatin hydrogels to demonstrate their enhanced activity to induce angiogenesis, or the regeneration of knee meniscus [31, 32], intervertebral disc [33-35], and bone tissues [25, 36].

In this study, mixed PRP growth factor mixture (PGFM) and bFGF were incorporated into the gelatin hydrogels for the multiple releases and the angiogenic effect was evaluated comparing with the release of either PGFM or bFGF from the hydrogels. We have been reported that neovascularization can be induced with controlled release of bFGF from gelatin hydrogel. The therapeutic neovasculariation generally involve both microvascular and macrovascular processes. At the microvasculatory level, angiogenesis is defined as the sprouting and growth of capillaries, which, however, regress after cessation 
of bFGF stimulation if pericytes are not recruited properly. Therefore, the stabilization of capillary networks newly created by mural cells (pericytes), known to be recruited by PDGF-BB, is essential for therapeutic neovascularization [37]. The process of capillaries maturation needs the recruitment of mural cells mediated by PDGF-BB [37, 38]. Taken together, in this study, we tried the multiple controlled release of PGFM and bFGF from the gelatin hydrogel to investigate the maturation of blood vessels newly formed in a murine model of hind limb ischemia. Following the intramuscular injection of gelatin hydrogel granules incorporating mixed PGFM and bFGF into a ischemia model animal. The in vivo angiogenesis was evaluated in terms of histological and laser Doppler perfusion imaging examinations. The $\mathrm{CaCl}_{2}$ treatment condition of PRP to allow to release platelet growth factors was optimized based on the amount of growth factor released and the release pattern from the hydrogels granules. We examine the time profile of representative platelet growth factors from the hydrogel granules comparing with that of hydrogel degradation. 


\section{Materials and methods}

\section{Preparation of gelatin hydrogel granules}

The gelatin sample of low endotoxin (beMatrix ${ }^{\circledR}$ Gelatin LS-H) with an isoelectric point (IEP) of 5.0, isolated by an alkaline process from the porcine skin, was kindly supplied from Nitta Gelatin Inc., Osaka, Japan. Biodegradable gelatin hydrogel granules were prepared by the glutaraldehyde (GA, Wako Pure Chemical Industries, Osaka, Japan) cross-linking of gelatin aqueous solution [6, 10, 11]. Briefly, after mixing $80 \mu \mathrm{l}$ of aqueous GA solution (25 wt $\%$ ) with $40 \mathrm{~g}$ of aqueous gelatin solution (5 wt $\%$ ) preheated at $40{ }^{\circ} \mathrm{C}$, the mixed aqueous solution was cast into a polystyrene dish $\left(127.8 \times 85.5 \mathrm{~mm}^{2}\right.$, Thermo Fisher Scientific Inc., MA, USA), followed by leaving for $12 \mathrm{hr}$ at $4{ }^{\circ} \mathrm{C}$ to allow the chemical cross-linking of gelatin. The resulting hydrogel sheets were then placed in $100 \mathrm{mM}$ glycine aqueous solution $(1 \ell)$, followed by agitation at room temperature for $1 \mathrm{hr}$ to block the residual aldehyde groups of unreacted GA.

The cross-linked hydrogel sheets were twice washed with double-distilled water (DDW). After washing, they were homogenized with Polytron PT-13000DM system (Central Scientific Commerce, Inc., Tokyo, Japan) and separated by sieves to obtain gelatin hydrogel granules at the diameter ranging from 32 to 52 $\mu \mathrm{m}$ in the DDW-swollen state. Thereafter, the hydrogel granules were freeze-dried, and sterilized with ethylene oxide gas. The water content of gelatin hydrogel granules (the weight ratio of water present in 
the hydrogel to the wet hydrogel) was $96 \mathrm{wt} \%$, when calculated from the hydrogel weight before and after swelling in phosphate-buffered saline solution (PBS, $\mathrm{pH} 7.4$ ) for $24 \mathrm{hr}$ at $37^{\circ} \mathrm{C}$.

\section{In vitro degradation assay}

To evaluate the pattern of hydrogel degradation, the gelatin hydrogel granules were agitated in two types of degradation solution $(1 \mathrm{ml})$, which is PBS with or without $10 \mu \mathrm{g} / \mathrm{ml}$ of collagenase (collagenase 1A, Nitta Gelatin Inc., Osaka, Japan) at $37^{\circ} \mathrm{C}$. At different time intervals, the solution supernatant was removed and replaced with the same volume of fresh PBS solution with or without collagenase. The gelatin concentration in each supernatant was determined by optical density (OD) measurement at $260 \mathrm{~nm}$ by spectrometer (DU800, Beckman Coulter, CA, USA) to evaluate the time profile of hydrogel degradation. Experiment was performed independently for 3 samples at every sampling time.

\section{Preparation of PRP and growth factors detection}

BALB/c mice (8 weeks old; Shimizu Laboratory Animal Supply, Kyoto, Japan) were used.

All animal experiments were approved by Kyoto University Committee for Animal Experimentation.

Briefly, 15 mice were anesthetized by the intraperitoneal injection of pentobarbital (somnopentyl, 
Kyoritsu Seiyaku, Tokyo, Japan) at a dose of $0.65 \mathrm{mg} / \mathrm{kg}$ body weights. PRP was prepared with a platelet-rich plasma kit (JP200; Japan Paramedic Co., Ltd, Tokyo, Japan) according to the method reported [39-41]. Briefly, animal bloods $(10 \mathrm{ml})$ were collected into tubes containing acid-citrate-dextrose solution formula A $(1: 4 \mathrm{vol} / \mathrm{vol})$ anticoagulant and centrifuged for $7 \mathrm{~min}$ at $450 \times \mathrm{G}$ and $4{ }^{\circ} \mathrm{C}$. Next, the yellow plasma with the buffy coat was carefully transferred into a BD Vacutainer ${ }^{\circledR}$ tube (Becton, Dickinson and Company, NJ, USA), and then centrifuged for 5 min at $1600 \times \mathrm{G}$ and $4{ }^{\circ} \mathrm{C}$. The platelet pellet was collected and the thrombolytic pellet in $1.0 \mathrm{ml}$ of plasma was used as PRP while the supernatant was done for platelet-poor plasma (PPP). Before and after the PRP preparation, an aliquot was taken out to count the number of platelets. The density of platelets in the PRP prepared was increased by a factor of 5 when compared with that of the original blood.

To activate PRP for the growth factors release, the PRP prepared was mixed with $\mathrm{CaCl}_{2}$ solution at concentrations of $0.4,0.6,0.8,1,2,4$, and $10 \mathrm{wt} \%$ at the vol/vol ratio of $7: 1$, followed by leaving for $1 \mathrm{hr}$ at $37^{\circ} \mathrm{C}$. As controls, PRP was treated with mixed $2 \mathrm{wt} \% \mathrm{CaCl} 2$ and thrombin solution or the conventional freeze-and thaw method [42-44]. Briefly, PRP was frozen by liquid nitrogen for 1 min, and then rapidly thaw at $25^{\circ} \mathrm{C}$. The process was repeated 3 times.

The amount of growth factors, such as PDGF-BB, VEGF, EGF, and TGF- $\beta_{1}$, released was 
determined with Quantikine ${ }^{\circledR}$ enzyme-linked immunosorbent assay (ELISA) kit (R\&D Systems, MN,

USA), respectively. For TGF- $\beta_{1}$ ELISA, the samples were first treated with acid to lower the $\mathrm{pH}$ to 2.0 to denature latency-associated peptide to allow the detection of active TGF- $\beta_{1}$. The supernatant was adjusted to the neutral $\mathrm{pH}$ before ELISA.

\section{Evaluation of PDGF-BB desorption from gelatin hydrogel granules incorporating PGFM}

To evaluate the extent of platelet growth factors impregnated into the gelatin hydrogel

granules, the amount of growth factors desorbed from gelatin hydrogel granules incorporating PGFM with or without $\mathrm{CaCl}_{2}$ treatment. The PRP was incubated with $\mathrm{CaCl}_{2}$ solution at different $\mathrm{Ca}^{2+}$ concentration for $1 \mathrm{hr}$ at $37{ }^{\circ} \mathrm{C}$ or treated with the freeze-and-thaw for 3 times. Then, $100 \mu \mathrm{l}$ of treatedand non-treated-PRP was impregnated into $10 \mathrm{mg}$ of freeze-dried gelatin hydrogel granules for $1 \mathrm{hr}$ at $37^{\circ} \mathrm{C}$. The gelatin hydrogel granules incorporating PGFM were placed in $1 \mathrm{ml}$ of PBS, and incubate for 3 $\mathrm{hr}$ at $37^{\circ} \mathrm{C}$. The amount of growth factors in each PBS sample was determined by the ELISA similarly.

The percent adsorption of growth factors to gelatin hydrogel granules was calculated by the following 
formula.

Percent adsorption $=100-($ the amount of desorbed growth factor $/$ the amount of impregnated growth factor $\times 100)$.

The experiment was done independently three times for each granule.

Preparation of gelatin hydrogel granules incorporating mixed PRP treated and bFGF

An aqueous solution of human recombinant bFGF with an IEP of $9.6(10 \mathrm{mg} / \mathrm{ml})$ was kindly

supplied by Kaken Pharmaceutical (Tokyo, Japan). The original bFGF solution was diluted with physiological saline solution (Otsuka pharmaceutical Co., Ltd. Tokyo, Japan) to give the solution concentration of $10 \mathrm{mg} / \mathrm{ml}$. The aqueous solution containing $100 \mu \mathrm{g}$ of bFGF (10 $\mu \mathrm{l})$ and $100 \mu \mathrm{l}$ of PGFM were dropped onto a freeze-dried gelatin hydrogel granule for impregnation of PGFM and bFGF into the granule. The bFGF and PGFM solutions were completely sorbed into the hydrogel granule by swelling at $37{ }^{\circ} \mathrm{C}$ for $1 \mathrm{hr}$, because the solution volume was less than theoretically required for the equilibrated swelling of hydrogels. Similarly, empty gelatin hydrogels without bFGF were prepared by adding PBS as the solution. 


\section{Release test of bFGF from gelatin hydrogel granules incorporating mixed PGFM and bFGF}

To evaluate the bFGF release from the gelatin hydrogel granules incorporating mixed PGFM

and bFGF, the gelatin hydrogels incorporating mixed PGFM and RI labeled-bFGF were incubated in two

types of release solution $(1 \mathrm{ml})$, which are PBS with and without $10 \mu \mathrm{g} / \mathrm{ml}$ of collagenase at $37^{\circ} \mathrm{C}$. After

$6 \mathrm{hr}$ incubation in PBS, there was a change from PBS to PBS with collagenase. At different time intervals, the solution supernatant was removed and replaced with the same volume of fresh PBS solution with or without collagenase. In this experiment, the PRP was treated with $2 \mathrm{wt} \% \mathrm{CaCl}_{2}$ solution for platelet activation, and bFGF was labeled with ${ }^{125} \mathrm{I}$.

Basic FGF was radioiodinated with chloramine-T according to the method described by Greenwood et al. [45]. Briefly, $5 \mu \mathrm{l}$ of $\mathrm{Na}^{125} \mathrm{I}$ was added to $200 \mu \mathrm{l}$ of $0.5 \mathrm{mg} / \mathrm{ml} \mathrm{bFGF}$ solution in $0.5 \mathrm{M}$ potassium PBS ( $\mathrm{pH} 7.5$ ) containing $0.5 \mathrm{M}$ sodium chloride. Then $0.2 \mathrm{mg} / \mathrm{ml}$ of chloramine-T in $0.5 \mathrm{M}$ potassium PBS ( $\mathrm{pH} 7.5)$ containing 0.5 M sodium chloride (100 $\mu \mathrm{l}$ ) was added to the solution mixture. After agitation at room temperature for $2 \mathrm{~min}, 100 \mu \mathrm{l}$ solution containing $0.4 \mathrm{mg}$ of sodium metabisulfate was added to the reaction solution to stop the radioiodination. The reaction mixture was passed through an anionic-exchange column to remove the uncoupled, free ${ }^{125} \mathrm{I}$ molecules from the ${ }^{125} \mathrm{I}$-labeled bFGF.

The mixture of the aqueous solution containing $100 \mu \mathrm{g}$ of ${ }^{125}$ I labeled-bFGF (10 $\left.\mu \mathrm{l}\right)$ and 100 
$\mu \mathrm{l}$ of PGFM was impregnated into $10 \mathrm{mg}$ of freeze-dried gelatin hydrogel granules for $1 \mathrm{hr}$ at $37^{\circ} \mathrm{C}$. The supernatant was sampled at scheduled times and the amount of bFGF in each supernatant samples were determined by the $\gamma$-counter. The experiment was done independently three times for each granule.

\section{Release test of PDGF-BB from gelatin hydrogel granules incorporating PGFM}

To evaluate the platelet PDGF-BB release from the gelatin hydrogel granules incorporating

PGFM, the gelatin hydrogels incorporating PGFM were incubated in two types of release solution $(1 \mathrm{ml})$,

which are PBS with and without $10 \mu \mathrm{g} / \mathrm{ml}$ of collagenase at $37^{\circ} \mathrm{C}$. After $12 \mathrm{hr}$ incubation in PBS, there was a change from PBS to PBS with collagenase. At different time intervals, the solution supernatant was removed and replaced with the same volume of fresh PBS solution with or without collagenase. In this experiment, the PRP was treated with $2 \mathrm{wt} \% \mathrm{CaCl}_{2}$ solution for platelet activation, and $100 \mu \mathrm{l}$ of treated PRP was impregnated into $10 \mathrm{mg}$ of freeze-dried gelatin hydrogel granules for $1 \mathrm{hr}$ at $37{ }^{\circ} \mathrm{C}$. The supernatant was sampled at scheduled times and the amount of PDGF-BB in each supernatant samples were determined by the ELISA similarly. The experiment was done independently three times for each granule. 


\section{In vivo experiments}

Hind limb ischemia was created in 8-week-old male BALB/c mice. Briefly, after the mice were anesthetized by an intraperitoneal pentobarbital $(0.65 \mathrm{mg} / \mathrm{kg})$ injection, the right groin area was shaved. The entire right saphenous artery and vein, right external iliac artery and vein, and deep femoral and circumflex arteries and vein were ligated, cut, and excised to obtain a murine model of severe hind limb ischemia. The BALB/c mice treated were randomly classified to 6 groups ( $\mathrm{n}=10$ per groups): hydrogel granules incorporating mixed PGFM and bFGF (PGFM + bFGF), gelatin hydrogel granules incorporating either PGFM or bFGF (PGFM or bFGF), gelatin hydrogel granules incorporating PPP (PPP), no-treatment (NT), and PGFM- and bFGF-free PBS (PBS). All drugs were homogeneously injected into 5 sites in the thigh muscle of mouse ischemic hind limb by using a 27-gauge needle.

The animals were re-anesthetized by an intraperitoneal injection of pentbarbital $(0.65 \mathrm{mg} / \mathrm{kg})$

1 wk after treatment, and the following measurements were performed to evaluate the in vivo angiogenesis. Each experiment was done three times independently otherwise mentioned.

\section{Hind limb Blood perfusion}

Hind limb blood perfusion was assessed by using a laser Doppler blood perfusion image 
(LDPI) analyzer (moorLDI ${ }^{\mathrm{TM}}$, Moor Instruments, Deven, UK) 1 wk after treatment [14]. To evaluate the influence of surgical procedure on the blood flow, the blood perfusion of normal hind limb and treated one were measured with LDPI. To minimize external influence, such as light and temperature, the perfusion result was expressed as the LDPI index which is the ratio of the blood perfusion in the right (ischemic) limb to that in the left (non-ischemic) limb of the same mouse $[14,18,46]$. The blood flow was measured in the site of vascular resection.

\section{Histological examination}

The specimens of muscular tissues were fixed with $4 \mathrm{wt} \%$ paraformaldehyde (PFA) in $0.1 \mathrm{M}$

phosphate-buffered solution for overnight at $4{ }^{\circ} \mathrm{C}$ and decalcified with Plank-Rychlo's solution overnight at room temperature. After decalcification, the samples were embedded in paraffin. Each specimen was cut into slices of the thigh, $4 \mu \mathrm{m}$ thick of cross section. For histological analysis, the section was stained with hematoxylin and eosin (HE) dyes, the number of blood vessels newly formed in the thigh was counted in a blind fashion. The number ratio of blood vessels newly formed in the right (ischemic) limb that in the left (non-ischemic) limb of the same mouse was calculated. 


\section{Immunohistological analysis}

The animals were re-anesthetized by an intraperitoneal injection of pentbarbital $(0.65 \mathrm{mg} / \mathrm{kg})$

1 week after treatment, and the mice were perfusion-fixed with $4 \mathrm{wt} \%$ PFA solution. The ischemic thigh was decalcified and embedded in paraffin. Paraffin sections (5 $\mu \mathrm{m}$ thickness $)$ of tissues were stained with a mouse monoclonal anti- $\alpha$-smooth muscle actin antibody ( $\alpha-$ SMA; Sigma-Aldrich Japan K.K., Tokyo, Japan). From each mouse, all fields on tissue sections were photographed with a digital camera (Olympus, Tokyo, Japan). The number of $\alpha$-SMA (vascular smooth muscle marker)-positive vessels was counted in a blind fashion. The number of blood vessels was counted for HE staining section. The percentage of number of $\alpha$-SMA-positive blood vessels to that of total blood vessels was calculated. Each experiment was done three times independently.

\section{Statistical analysis}

All the statistical data were expressed as the mean \pm standard error of the mean. The data were analyzed by ANOVA to determine the statistical significance between the two mean values. The $p$ value less than 0.05 were considered to be significant. 


\section{Results}

\section{$\mathrm{CaCl}_{2}$ treatment of PRP for the release of platelet growth factors}

Table 1 shows the concentration of various growth factors released from PRP after the freeze-and-thaw treatment. The treatment activated the platelet of PRP to release various growth factors.

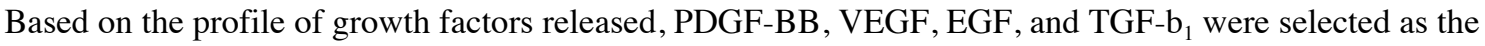
representative platelet growth factor because of the highest amount and the activity to enhance the maturation of blood vessels newly formed [38, 47-53].

Figure 1 shows the concentration of PDGF-BB released from PRP after the $\mathrm{CaCl}_{2}$ treatment. Upon treating with $0.8,1,2$, and $4 \mathrm{wt} \%$ of $\mathrm{CaCl}_{2}$ solution, the concentration of PDGF-BB in the soluble fraction of PRP was significantly high compared with that of non-treated PRP. On the other hand, the treatment of $10 \mathrm{wt} \% \mathrm{CaCl}_{2}$ solution did not increase the PDGF-BB amount. The concentration of EGF in the soluble fraction of PRP was significantly high compared with the non-treated PRP and the 10 wt $\%$ $\mathrm{CaCl}_{2}$ solution treated PRP (Figure 2A). The amount of VEGF extracted from PRP was higher in PRP treated with $\mathrm{CaCl}_{2}$ compared with that of non-treatment (Figure 2B). In this study, PDGF was noted because it has on ability to enhance the maturation of blood vessels. In addition, PDGF is one of the main 
factors present in PRP. On the contrary, the amount of TGF- $\beta_{1}$ in PRP treated with 1,2 , and 4 wt $\% \mathrm{CaCl}_{2}$ was higher than that of $10 \mathrm{wt} \% \mathrm{CaCl}_{2}$ treated PRP, although it was not significant (Figure 2C).

Adsorption of growth factors to gelatin hydrogel granules incorporating PGFM and the in vitro profiles of PDGF-BB release

Figure 3 shows the adsorption patterns of growth factors to gelatin hydrogel granules incorporating PGFM. For PRP treated with $0.8,1,2$, and $4 \mathrm{wt} \% \mathrm{CaCl}_{2}$ for $1 \mathrm{hr}$ at $37^{\circ} \mathrm{C}$, the amount of PDGF-BB adsorption was significantly low compared with that treated with 0.4 and $0.6 \mathrm{wt} \% \mathrm{CaCl}_{2}$ (Figure $3 \mathrm{~A}$ ). The pattern of VEGF, EGF and TGF- $\beta_{1}$ adsorption from the hydrogel granules incorporating PGFM was influenced by the $\mathrm{CaCl}_{2}$ concentration (Figures $3 \mathrm{~B}, \mathrm{C}$, and D). On the other hand, Figure 4 shows the adsorption patterns of growth factors to gelatin hydrogel granules incorporating mixed PGFM and bFGF and time courses of bFGF from gelatin hydrogel granules incorporating mixed PGFM and bFGF in PBS with or without collagenase. When mixed PGFM and bFGF were impregnated to gelatin hydrogel granules, the adsorption rate of bFGF to gelatin hydrogel granules was about $50 \%$ of impregnated bFGF (Figure 4A). In the release in PBS, about $60 \%$ of bFGF was released from the hydrogel granules. When 
mixed PGFM and bFGF were impregnated to gelatin hydrogel granules, the initial burst of bFGF was increased compared with that of single impregnation of bFGF. However, when the release test was performed in PBS containing collagenase, the bFGF was release with time (Figure 4B).

Figure 5 shows the time courses of PDGF-BB from gelatin hydrogel granules incorporating PRP treated with 2 wt $\% \mathrm{CaCl}_{2}$ solution in PBS with or without collagenase. In the release in PBS, PDGF-BB was not released from the hydrogel granules, although the initial burst of small amount in release was observed. However, when the release test was performed in PBS containing collagenase, the PDGF-BB was release with time. The similar addition effect of collagenase on the time profile of hydrogel degradation was seen. A good correlation of time profiles was observed between the PDGF-BB release and the hydrogel degradation.

\section{Angiogenic effects of gelatin hydrogel granules incorporating mixed PGFM and bFGF}

Figure 6 shows the in vivo angiogenic effects of gelatin hydrogel granules incorporating PGFM with or without bFGF combination 1 week after implantation. The PRP was treated with 2 wt $\%$

$\mathrm{CaCl}_{2}$ solution. From the histological sections, the new formation of blood vessels was observed for the hydrogel granules incorporating mixed PGFM and bFGF. The number of blood vessels newly formed 
was significantly high compared with that of other groups. The vessels number was not increased by injection of hydrogel granules incorporating PGFM, bFGF or PBS. PBS solution containing PGFM, bFGF or mixed PGFM and bFGF did not increase the number of new blood vessels (data not shown). The percentage of $\alpha$-SMA-positive blood vessels increased by the granules incorporating mixed PGFM and bFGF to a significantly high extent compared with that of other controls. No difference in the vessels number between the right and left limbs was observed for the non-treated and empty granules injected groups. This indicates that neither the surgical procedure nor the granules injection induced angiogenesis.

Figure 7 shows blood perfusion levels in the ischemic limb after the injection of different gelatin hydrogel granules incorporating mixed PGFM and bFGF. The injection of hydrogel granules incorporating mixed PGFM and bFGF significantly enhanced the perfusion index, in remarked contrast to that of other groups. 


\section{Discussion}

The present study demonstrates that the multiple releases of PRP growth factors and bFGF from gelatin hydrogel granules was effective in increasing the number of blood vessels newly formed and the blood flow level in the ischemic legs. In addition, the number of $\alpha$-SMA-positive blood vessels was also increased, which suggests the maturation enhancement of blood vessels.

In the living tissue, it is well known that various growth factors interact with the components of extracellular matrix, such as acidic polysaccharides and collagen, through various intermolecular interaction forces [54]. In addition, the physicochemical interactions serve to maintain and enhance the in vivo biological function of growth factors. For instance, bFGF with an IEP of 9.6 forms polyion complexes with heparin and heparan sulfate in vivo, resulting in the stabilization and regulation of biological activities $[43,55]$. The manner of natural physicochemical interactions is a good example to design the controlled release system of growth factors. Based on this, we have developed the biodegradable hydrogels of gelatin $[9-11,56]$. The physicochemical property of gelatin, such as the electric nature, can be readily modified by the preparation procedure. For example, gelatin prepared with an alkaline process from collagen has an IEP of 5.0 and is negatively charged at the physiological $\mathrm{pH}$, whereas an acidic process of collagen gives a positively charged gelatin with an IEP of 9.0. This electric 
nature of gelatin can be used to interact electrostatically with growth factors of different IEPs [56].

Recently, human recombinant growth factors have become commercially available and have been experimentally or clinically used for tissue regeneration applications. However, only when the growth factor in the solution form is used in vivo, the biological activity is not always expected. This is because it is un-stable in vivo due to the rapid enzymatic digestion or deactivation. Therefore, their delivery technology is highly required to enable the growth factor to efficiently enhance the biological functions. We have succeeded in the controlled release of various growth factors as well as PRP from the gelatin hydrogels [6-13]. It has been recognized that when activated, the platelets of PRP release various growth factors through the degranulation of $\alpha$ granules and the factors released exhibit various biological activities [23]. For example, collagen and thrombin trigger the platelets aggregation and the subsequent release of platelet growth factors [57]. It is experimentally confirmed that the gelatin of a denatured collagen can function to trigger the platelet activation for growth factor release [36]. When impregnated into the hydrogel freeze-dried, it is likely that the PRP is activated by the contact with gelatin molecules to release the growth factors. The factors released interact with gelatin molecules during the impregnation procedure. Consequently, the PRP growth factors can be released from the gelatin hydrogels as a result of the hydrogel degradation. However, the contact of PRP with gelatin molecules is not always strong 
enough to release out the PRP growth factors. In this study, the treatment of PRP with $\mathrm{CaCl}_{2}$ solution was tried to accelerate the release of PRP growth factors. The $\mathrm{CaCl}_{2}$ treatment is one of the well-known methods to activate PRP $[41,58]$.

The adsorption experiment demonstrated that the percent of PRP growth factors desorbed increased with decrease in the $\mathrm{CaCl}_{2}$ concentration. This can be explained in terms of solution ionic strength. It is recognized that the growth factor physicochemically interacts with the gelatin molecules of hydrogels while one of the main interactions is the electrostatic. It is, therefore, likely that the increased $\mathrm{CaCl}_{2}$ concentration suppresses the interaction between the PRP growth factor and gelatin molecules, resulting in increased the desorption percentage. In addition, the pattern of PDGF-BB release from the hydrogel granules incorporating PGFM is influenced by the $\mathrm{CaCl}_{2}$ concentration. When the concentration was $4 \mathrm{wt} \%$, higher amount of PDGF-BB release for the initial time period was observed compared with that of granules incorporating PGFM treated with $2 \mathrm{wt} \% \mathrm{CaCl}_{2}$ solution. Taken together, the $\mathrm{CaCl}_{2}$ concentration for PRP treatment was fixed at $2 \mathrm{wt} \%$. The time profile of PDGF-BB release from the granules incorporating $2 \mathrm{wt} \% \mathrm{CaCl}_{2}$ treated-PRP was in a good accordance with that of granules degradation. This indicates that the growth factor release is based on the degradation of release carrier hydrogels. When PRP treated with the freeze-and-thaw method, the concentration of PDGF-BB in the 
soluble fraction of PRP was significantly high compared with that of $\mathrm{CaCl}_{2}$-treated PRP. However, the activation of PRP by the freeze-and-thaw method is not always suitable because of the complicated process in clinic.

The $\mathrm{CaCl}_{2}$ treatment affects the amount of platelet growth factor released and the adsorption profile to the hydrogel granules incorporating PGFM (Figures 1 and 2). In this study, PDGF-BB, VEGF, EGF, and TGF- $\beta_{1}$ were selected as the representative platelet growth factor because of the high amount and the activity to enhance the maturation of blood vessels newly formed $[47-49,51,53,59]$. In the $\mathrm{CaCl}_{2}$ concentration of 1,2 , and $4 \mathrm{wt} \%$, the amount of growth factors was higher than that of higher or lower $\mathrm{CaCl}_{2}$ concentrations. The treatment at the lower concentration would be not enough to activate the platelet. On the other hand, it is possible that the strong activation of platelet with $\mathrm{CaCl}_{2}$ solution of higher concentration results in the release out of platelet ingredients. The ingredients may suppress the activity of platelet growth factor.

We have demonstrated successful angiogenic effects on ischemic legs and hearts by biodegradable acidic gelatin hydrogels for the controlled release of bFGF $[10,11]$. The bFGF release from the gelatin hydrogels was therapeutically effective in various animal models (i.e., either non-diabetic or diabetic) for acute myocardial infarction, prevascularization for cardiomyocyte transplantation to the 
ischemic heart, limb ischemia, and bone regeneration of sternum [14-21]. In the release system, both the biodegradable gelatin hydrogels of release carrier and the bFGF of an angiogenic factor are clinically available at present. Based on the results of animal experiments, several clinical trials have been started to confirm the safety and feasibility of bFGF release from the gelatin hydrogel in patients with clinical limb ischemia. The gelatin hydrogel for bFGF release is simple, safe, and effective from the clinical viewpoint. It is not necessary to use genetic materials and collect cells to be transplanted. In addition, no elevation of bFGF serum level was reported in the clinical case [22]. However, the bFGF release system has some rooms to be improved for the clinical applications. It is practically necessary for the treatment of patients with severe conditions to enhance the number of blood vessels newly formed and their biological maturation. The enhancement of blood vessels maturation is one of the practical strategies to treat such patients in the severe condition. There are several researches on the maturation of blood vessels in terms of growth factors usage. PRP is a source of autologous growth factors, including PDGF-BB, VEGF, EGF, and TGF- $\beta$. Several growth factors become intricately involved in angiogenesis. The PDGF-BB, VEGF, and TGF- $\beta$ play an important role as proangiogenic stimulators. Several studies reported that PDGF-BB has a potent arteriogenic effect that promotes differentiation of endothelial cells [60], and VEGF is known to stimulate angiogenesis after ischemia [61], and TGF- $\beta$ promote cell mitosis [53]. However, other 
studies indicated that several growth factors, such as PDGF-BB and TGF- $\beta$, inhibit the angiogenic effect of bFGF [62-65]. These studies were evaluating the angiogenic effect using mixed solution of growth factors. Moreover, the amounts of growth factors was used transiently at high concentration. On the other hand, we used gelatin hydrogel granules incorporating PGFM and bFGF in this study, this gelatin hydrogel granules was degraded for 2 weeks, and sustained release the encapsulated growth factors. Thus, our sustained-release system and previous reports are fundamentally different. Among them, PDGF-BB is one of the powerful growth factors to allow the blood vessels to mature functionally $[38,49]$. The finding gives us the idea that the multiple releases of PGFM and bFGF will enhance the maturation of blood vessels. Mooney et al. reported that the dual release of VEGF and PDGF enhanced the maturation of blood vessels newly formed compared with that of single VEGF release. The in vivo experiments clearly indicate that the dual release of PRP treated and bFGF from the biodegradable gelatin hydrogel granules promoted not only angiogenesis in a mouse model of limb ischemia, but also the maturation of blood vessels whereas the release of either PGFM or bFGF was not effective. There have been reported on the synergistic effects of different drugs on the enhancement of tissue regeneration [66-68] and tissue maturation. The dual release technology is available for any type of drug and to promote the regeneration of various tissues. 


\section{References}

1. Blau H, Khavari P. Gene therapy: progress, problems, prospects. Nat Med 1997 Jun;3(6):612-613.

2. Chuah MK, Collen D, VandenDriessche T. Biosafety of adenoviral vectors. Curr Gene Ther 2003 Dec;3(6):527-543.

3. Howe SJ, Mansour MR, Schwarzwaelder K, Bartholomae C, Hubank M, Kempski H, et al. Insertional mutagenesis combined with acquired somatic mutations causes leukemogenesis following gene therapy of SCID-X1 patients. J Clin Invest 2008 Sep;118(9):3143-3150.

4. Kai S, Hara H. Allogeneic hematopoietic stem cell transplantation. Ther Apher Dial 2003 Jun;7(3):285-291.

5. Steward CG, Jarisch A. Haemopoietic stem cell transplantation for genetic disorders. Arch Dis Child 2005 Dec;90(12):1259-1263.

6. Ozeki M, Tabata Y. Promoted Growth of Murine Hair Follicles through Controlled Release of Basic Fibroblast Growth Factor. Tissue Engineering 2002;8(3):359-366.

7. Hong L, Tabata Y, Miyamoto S, Yamamoto M, Yamada K, Hashimoto N, et al. Bone 
regeneration at rabbit skull defects treated with transforming growth factor-betal incorporated into hydrogels with different levels of biodegradability. J Neurosurg 2000 Feb;92(2):315-325.

8. Kanematsu A, Yamamoto S, Ozeki M, Noguchi T, Kanatani I, Ogawa O, et al. Collagenous matrices as release carriers of exogenous growth factors. Biomaterials 2004 Aug;25(18):4513-4520.

9. Yamamoto M, Takahashi Y, Tabata Y. Enhanced bone regeneration at a segmental bone defect by controlled release of bone morphogenetic protein-2 from a biodegradable hydrogel. Tissue Eng 2006 May;12(5):1305-1311.

10. Tabata Y, Hijikata S, Ikada Y. Enhanced vascularization and tissue granulation by basic fibroblast growth factor impregnated in gelatin hydrogels. Journal of Controlled Release 1994;31(2):189-199.

11. Tabata Y, Hijikata S, Muniruzzaman M, Ikada Y. Neovascularization effect of biodegradable gelatin microspheres incorporating basic fibroblast growth factor. J Biomater Sci Polym Ed 1999;10(1):79-94.

12. Ozeki M, Tabata Y. Affinity evaluation of gelatin for hepatocyte growth factor of different types to design the release carrier. J Biomater Sci Polym Ed 2006;17(1-2):139-150.

13. Sakaguchi G, Tambara K, Sakakibara Y, Ozeki M, Yamamoto M, Premaratne G, et al. 
Control-released hepatocyte growth factor prevents the progression of heart failure in stroke-prone spontaneously hypertensive rats. Ann Thorac Surg 2005 May;79(5):1627-1634.

14. Arai Y, Fujita M, Marui A, Hirose K, Sakaguchi H, Ikeda T, et al. Combined Treatment With Sustained-Release Basic Fibroblast Growth Factor and Heparin Enhances Neovascularization in Hypercholesterolemic Mouse Hindlimb Ischemia. Circulation Journal 2007;71(3):412-417.

15. Hirose K, Fujita M, Marui A, Arai Y, Sakaguchi H, Huang Y, et al. Combined treatment of sustained-release basic fibroblast growth factor and sarpogrelate enhances collateral blood flow effectively in rabbit hindlimb ischemia. Circ J 2006 Sep;70(9):1190-1194.

16. Hirose K, Marui A, Arai Y, Fujita M, Nomura T, Mitsuyama M, et al. Sustained-release form of basic fibroblast growth factor prevents catheter-related bacterial invasion in mice. Interact Cardiovasc Thorac Surg 2005 Dec;4(6):526-530.

17. Iwakura A, Tabata Y, Tamura N, Doi K, Nishimura K, Nakamura T, et al. Gelatin sheet incorporating basic fibroblast growth factor enhances healing of devascularized sternum in diabetic rats.

Circulation 2001 Sep 18;104(12 Suppl 1):I325-329.

18. Marui A, Kanematsu A, Yamahara K, Doi K, Kushibiki T, Yamamoto M, et al. Simultaneous application of basic fibroblast growth factor and hepatocyte growth factor to enhance the blood vessels 
formation. J Vasc Surg 2005 Jan;41(1):82-90.

19.

Sakakibara Y, Nishimura K, Tambara K, Yamamoto M, Lu F, Tabata Y, et al.

Prevascularization with gelatin microspheres containing basic fibroblast growth factor enhances the

benefits of cardiomyocyte transplantation. J Thorac Cardiovasc Surg 2002 Jul;124(1):50-56.

20. Takaba K, Jiang C, Nemoto S, Saji Y, Ikeda T, Urayama S, et al. A combination of omental

flap and growth factor therapy induces arteriogenesis and increases myocardial perfusion in chronic

myocardial ischemia: evolving concept of biologic coronary artery bypass grafting. J Thorac Cardiovasc

Surg 2006 Oct;132(4):891-899.

21. Tambara K, Premaratne GU, Sakaguchi G, Kanemitsu N, Lin X, Nakajima H, et al.

Administration of control-released hepatocyte growth factor enhances the efficacy of skeletal myoblast

transplantation in rat infarcted hearts by greatly increasing both quantity and quality of the graft.

Circulation 2005 Aug 30;112(9 Suppl):I129-134.

22. Marui A, Tabata Y, Kojima S, Yamamoto M, Tambara K, Nishina T, et al. A novel approach

to therapeutic angiogenesis for patients with critical limb ischemia by sustained release of basic fibroblast

growth factor using biodegradable gelatin hydrogel: an initial report of the phase I-IIa study. Circ J 2007

Aug;71(8):1181-1186. 
23. Marx RE. Platelet-rich plasma: evidence to support its use. J Oral Maxillofac Surg 2004 Apr;62(4):489-496.

24. Margolis DJ, Kantor J, Santanna J, Strom BL, Berlin JA. Effectiveness of platelet releasate for the treatment of diabetic neuropathic foot ulcers. Diabetes Care 2001 Mar;24(3):483-488.

25. Hokugo A, Sawada Y, Hokugo R, Iwamura H, Kobuchi M, Kambara T, et al. Controlled release of platelet growth factors enhances bone regeneration at rabbit calvaria. Oral Surg Oral Med Oral Pathol Oral Radiol Endod 2007 Jul;104(1):44-48.

26. Marx RE, Carlson ER, Eichstaedt RM, Schimmele SR, Strauss JE, Georgeff KR. Platelet-rich plasma: Growth factor enhancement for bone grafts. Oral Surg Oral Med Oral Pathol Oral Radiol Endod 1998 Jun;85(6):638-646.

27. Bhanot S, Alex JC. Current applications of platelet gels in facial plastic surgery. Facial Plast Surg 2002 Feb;18(1):27-33.

28. Man D, Plosker H, Winland-Brown JE. The use of autologous platelet-rich plasma (platelet gel) and autologous platelet-poor plasma (fibrin glue) in cosmetic surgery. Plast Reconstr Surg 2001 Jan;107(1):229-237; discussion 238-229.

29. Hee HT, Majd ME, Holt RT, Myers L. Do autologous growth factors enhance transforaminal 
lumbar interbody fusion? European Spine Journal 2003;12(4):400-407.

30.

Bir SC, Esaki J, Marui A, Yamahara K, Tsubota H, Ikeda T, et al. Angiogenic properties of

sustained release platelet-rich plasma: Characterization in-vitro and in the ischemic hind limb of the mouse. Journal of Vascular Surgery 2009;50(4):870-879.e872.

31. Ishida K, Kuroda R, Miwa M, Tabata Y, Hokugo A, Kawamoto T, et al. The regenerative effects of platelet-rich plasma on meniscal cells in vitro and its in vivo application with biodegradable gelatin hydrogel. Tissue Eng 2007 May;13(5):1103-1112.

32. Saito M, Takahashi KA, Arai Y, Inoue A, Sakao K, Tonomura H, et al. Intraarticular administration of platelet-rich plasma with biodegradable gelatin hydrogel microspheres prevents osteoarthritis progression in the rabbit knee. Clin Exp Rheumatol 2009 Mar-Apr;27(2):201-207.

33. Nagae M, Ikeda T, Mikami Y, Hase H, Ozawa H, Matsuda K, et al. Intervertebral disc regeneration using platelet-rich plasma and biodegradable gelatin hydrogel microspheres. Tissue Eng 2007 Jan;13(1):147-158.

34. Okamoto SI, Ikeda T, Sawamura K, Nagae M, Hase H, Mikami Y, et al. Positive Effect on Bone Fusion by the Combination of Platelet-Rich Plasma and a Gelatin beta-Tricalcium Phosphate Sponge: A Study Using a Posterolateral Fusion Model of Lumbar Vertebrae in Rats. Tissue Eng Part A 
2011 Sep 21.

35. Sawamura K, Ikeda T, Nagae M, Okamoto S, Mikami Y, Hase H, et al. Characterization of in vivo effects of platelet-rich plasma and biodegradable gelatin hydrogel microspheres on degenerated intervertebral discs. Tissue Eng Part A 2009 Dec;15(12):3719-3727.

36. Hokugo A, Ozeki M, Kawakami O, Sugimoto K, Mushimoto K, Morita S, et al. Augmented bone regeneration activity of platelet-rich plasma by biodegradable gelatin hydrogel. Tissue Eng 2005 Jul-Aug;11(7-8):1224-1233.

37. Jain RK. Molecular regulation of vessel maturation. Nat Med 2003 Jun;9(6):685-693.

38. Zymek P, Bujak M, Chatila K, Cieslak A, Thakker G, Entman ML, et al. The role of platelet-derived growth factor signaling in healing myocardial infarcts. J Am Coll Cardiol 2006 Dec 5;48(11):2315-2323.

39. Aghaloo TL, Moy PK, Freymiller EG. Investigation of platelet-rich plasma in rabbit cranial defects: A pilot study. J Oral Maxillofac Surg 2002 Oct;60(10):1176-1181.

40. Kazakos K, Lyras DN, Thomaidis V, Agrogiannis G, Botaitis S, Drosos G, et al. Application of PRP gel alone or in combination with guided bone regeneration does not enhance bone healing process: An experimental study in rabbits. J Craniomaxillofac Surg 2011 Jan;39(1):49-53. 
41. Marukawa E, Oshina H, Iino G, Morita K, Omura K. Reduction of bone resorption by the application of platelet-rich plasma (PRP) in bone grafting of the alveolar cleft. J Craniomaxillofac Surg 2010 Jun 7.

42. Doucet C, Ernou I, Zhang Y, Llense JR, Begot L, Holy X, et al. Platelet lysates promote mesenchymal stem cell expansion: a safety substitute for animal serum in cell-based therapy applications.

J Cell Physiol 2005 Nov;205(2):228-236.

43. Rifkin DB, Moscatelli D. Recent developments in the cell biology of basic fibroblast growth factor. J Cell Biol 1989 Jul;109(1):1-6.

44. Schallmoser K, Strunk D. Preparation of Pooled Human Platelet Lysate (pHPL) as an Efficient Supplement for Animal Serum-Free Human Stem Cell Cultures. J Vis Exp 2009(32):e1523.

45. Greenwood FC, Hunter WM, Gglover TC. The preparation of I-labeled human growth hormone of high specific radioactivity. Biochem J 1963;89:114.

46. Couffinhal T, Silver M, Zheng LP, Kearney M, Witzenbichler B, Isner JM. Mouse model of angiogenesis. Am J Pathol 1998 Jun;152(6):1667-1679.

47. Bertrand-Duchesne MP, Grenier D, Gagnon G. Epidermal growth factor released from platelet-rich plasma promotes endothelial cell proliferation in vitro. J Periodontal Res 2010 
Feb;45(1):87-93.

48. Gospodarowicz D, Greenburg G, Bialecki H, Zetter BR. Factors involved in the modulation of cell proliferation in vivo and in vitro: the role of fibroblast and epidermal growth factors in the proliferative response of mammalian cells. In Vitro 1978 Jan;14(1):85-118.

49. Hellberg C, Ostman A, Heldin CH. PDGF and vessel maturation. Recent Results Cancer Res 2010;180:103-114.

50. Munoz-Chapuli R. Evolution of angiogenesis. Int J Dev Biol 2011;55(4-5):345-351.

51. Nicosia RF, Nicosia SV, Smith M. Vascular endothelial growth factor, platelet-derived growth factor, and insulin-like growth factor-1 promote rat aortic angiogenesis in vitro. Am J Pathol 1994 Nov;145(5):1023-1029.

52. Ribatti D, Nico B, Crivellato E. The role of pericytes in angiogenesis. Int J Dev Biol 2011;55(3):261-268.

53. Schultz GS, Grant MB. Neovascular growth factors. Eye (Lond) 1991;5 ( Pt 2):170-180.

54. Taipale J, Keski-Oja J. Growth factors in the extracellular matrix. FASEB J 1997 Jan;11(1):51-59.

55. Gospodarowicz D. Biological Activities of Fibroblast Growth Factors. Annals of the New 
York Academy of Sciences 1991;638(1):1-8.

56. Yamamoto M, Ikada Y, Tabata Y. Controlled release of growth factors based on biodegradation of gelatin hydrogel. J Biomater Sci Polym Ed 2001;12(1):77-88.

57. Kaplan KL, Nossel HL, Drillings M, Lesznik G. Radioimmunoassay of platelet factor 4 and beta-thromboglobulin: development and application to studies of platelet release in relation to fibrinopeptide A generation. Br J Haematol 1978 May;39(1):129-146.

58. Kakudo N, Minakata T, Mitsui T, Kushida S, Notodihardjo FZ, Kusumoto K. Proliferation-promoting effect of platelet-rich plasma on human adipose-derived stem cells and human dermal fibroblasts. Plast Reconstr Surg 2008 Nov;122(5):1352-1360.

59. Bir SC, Esaki J, Marui A, Yamahara K, Tsubota H, Ikeda T, et al. Angiogenic properties of sustained release platelet-rich plasma: characterization in-vitro and in the ischemic hind limb of the mouse. J Vasc Surg 2009 Oct;50(4):870-879 e872.

60. Carmeliet P. Angiogenesis in health and disease. Nat Med 2003 Jun;9(6):653-660.

61. Ferrara N. Role of vascular endothelial growth factor in regulation of physiological angiogenesis. Am J Physiol Cell Physiol 2001 Jun;280(6):C1358-1366.

62. De Marchis F, Ribatti D, Giampietri C, Lentini A, Faraone D, Scoccianti M, et al. 
Platelet-derived growth factor inhibits basic fibroblast growth factor angiogenic properties in vitro and in vivo through its alpha receptor. Blood 2002 Mar 15;99(6):2045-2053.

63. Facchiano A, De Marchis F, Turchetti E, Facchiano F, Guglielmi M, Denaro A, et al. The chemotactic and mitogenic effects of platelet-derived growth factor-BB on rat aorta smooth muscle cells are inhibited by basic fibroblast growth factor. J Cell Sci 2000 Aug;113 ( Pt 16):2855-2863.

64. Muller G, Behrens J, Nussbaumer U, Bohlen P, Birchmeier W. Inhibitory action of transforming growth factor beta on endothelial cells. Proc Natl Acad Sci U S A 1987 Aug;84(16):5600-5604.

65. Tengood JE, Ridenour R, Brodsky R, Russell AJ, Little SR. Sequential delivery of basic fibroblast growth factor and platelet-derived growth factor for angiogenesis. Tissue Eng Part A 2011 May;17(9-10):1181-1189.

66. Patel ZS, Young S, Tabata Y, Jansen JA, Wong ME, Mikos AG. Dual delivery of an angiogenic and an osteogenic growth factor for bone regeneration in a critical size defect model. Bone 2008 Nov;43(5):931-940.

67. Peng H, Wright V, Usas A, Gearhart B, Shen HC, Cummins J, et al. Synergistic enhancement of bone formation and healing by stem cell-expressed VEGF and bone morphogenetic protein-4. J Clin 
Invest 2002 Sep;110(6):751-759.

68. Ratanavaraporn J, Furuya H, Kohara H, Tabata Y. Synergistic effects of the dual release of stromal cell-derived factor-1 and bone morphogenetic protein-2 from hydrogels on bone regeneration.

Biomaterials 2011 Apr;32(11):2797-2811. 


\section{Figure legend}

Figure 1.

Concentration of PDGF-BB released from PRP after the treatment of $\mathrm{CaCl}_{2}$ solution at different $\mathrm{Ca}^{2+}$ concentrations, the mixed solution of $2 \mathrm{wt} \% \mathrm{CaCl}_{2}$ and thrombin, and freeze-and-thaw treated. ${ }^{*}, \mathrm{p}<0.05$; significant different from the values of non-treated PRP.,$+ \mathrm{p}<0.05$; significant different from the values of $0.4 \mathrm{wt} \% \mathrm{CaCl}_{2}$-treated PRP. $\$, \mathrm{p}<0.05$; significant different from the values of $10 \mathrm{wt} \% \mathrm{CaCl}_{2}$-treated PRP.

Figure 2.

Concentration of growth factors released from PRP after the treatment of $\mathrm{CaCl}_{2}$ solution at different $\mathrm{Ca}^{2+}$ concentrations, the mixed solution of $2 \mathrm{wt} \% \mathrm{CaCl}_{2}$ and thrombin, and freeze-and-thaw treated. (A)

Concentration of EGF released from PRP. *, $\mathrm{p}<0.05$; significant different from the values of non-treated

PRP.,$+ \mathrm{p}<0.05$; significant different from the values of $10 \mathrm{wt} \% \mathrm{CaCl}_{2}$-treated PRP. $\neq, \mathrm{p}<0.05$; significant different from the values of freeze-and-thaw treated PRP. (B) Concentration of VEGF released from PRP.

*, $\mathrm{p}<0.05$; significant different from the values of freeze-and-thaw treated PRP. (C) Concentration of TGF- $\beta_{1}$ released from PRP. 
Figure 3.

Adsorption of growth factors to gelatin hydrogel granules. After treatment of $\mathrm{CaCl}_{2}$ solution at different

$\mathrm{Ca}^{2+}$ concentrations and the mixed solution of $2 \mathrm{wt} \% \mathrm{CaCl}_{2}$ and thrombin, the PRP treated was incorporated into the gelatin hydrogels at $37^{\circ} \mathrm{C}$ for $1 \mathrm{hr}$. The concentration of growth factors desorbed from gelatin hydrogel granules incorporating PGFM treated was detected by ELISA. (A) The percent adsorption of PDGF-BB to gelatin hydrogel. *, $\mathrm{p}<0.05$; significant different from the values of 0.4 wt $\% \mathrm{CaCl}_{2}$ treated PRP. $\uparrow, \mathrm{p}<0.05$; significant different from the values of $0.6 \mathrm{wt} \% \mathrm{CaCl}_{2}$ treated PRP. $\ddagger$, $\mathrm{p}<0.05$; significant different from the values of the mixed solution of $2 \mathrm{wt} \% \mathrm{CaCl}_{2}$ and thrombin. (B) The percent adsorption of VEGF to gelatin hydrogel. (C) The percent adsorption of EGF to gelatin hydrogel. (D) The percent adsorption of TGF- $\beta_{1}$ to gelatin hydrogel.

Figure 4.

Adsorption of bFGF to gelatin hydrogel granules and time course of bFGF release from gelatin hydrogel granules incorporating mixed PGFM and ${ }^{125}$ I-labeled bFGF. (A) The percent adsorption of bFGF to gelatin hydrogel. (B) The time course of bFGF release from gelatin hydrogel granules incorporating 
mixed PGFM and ${ }^{125}$ I-labeled bFGF $(\mathrm{O})$ and gelatin hydrogel granules incorporating ${ }^{125}$ I-labeled bFGF $(\bullet)$ in PBS with or without collagenase. The PBS solution was changed to that with collagenase at the time indicated with arrow.

Figure 5.

The time course of PDGF-BB release from gelatin hydrogel granules incorporating PRP treated with 2

wt $\% \mathrm{CaCl}_{2}$ solution (O) and hydrogel degradation (•) in PBS with or without collagenase. The PBS solution was changed to that with collagenase at the time indicated with arrow.

Figure 6.

In vivo angiogenic effects of gelatin hydrogel granules incorporating PRP with or without bFGF 1 week after implantation. (A) Histological section ((a-f) hematoxylin and eosin and (g-l) anti- $\alpha$-SMA immunohistochemical staining) of tissues injected with different gelatin hydrogel granules: (a, g) hydrogels incorporating PGFM and bFGF, (b, h) PGFM, (c, i) bFGF, (d, j) PPP or (e, k) PBS, and (f, l) non-treatment. The scale bar indicates $100 \mu \mathrm{m}$. (B) The number ratio of blood vessels newly formed around tissues injected with gelatin hydrogel granules. The number ratio of blood vessels newly formed 
in the right (ischemic) limb was calculated as for that in the left (non-ischemic) limb of the same mouse.

Ratio of 1.0 was calculated in non-treated mice. $*$, p $<0.05$; significant different from the value of gelatin

hydrogel granules incorporating PPP. $\uparrow, p<0.01$; significant different from the value of gelatin hydrogel

granules incorporating PBS. $\ddagger, \mathrm{p}<0.01$; significant different from the value of non-treatment. (C)

Percentage of anti- $\alpha$-SMA antibody positive blood vessels around the tissue injected with gelatin

hydrogel granules. The percentage of number of $\alpha$-SMA-positive blood vessels to that of total blood

vessels was calculated. *, $\mathrm{p}<0.05$; significant different from the value of gelatin hydrogel granules

incorporating PGFM.,$+ \mathrm{p}<0.05$; significant different from the value of gelatin hydrogel granules incorporating bFGF.

Figure 7.

In vivo blood perfusion effects of gelatin hydrogel granules incorporating PGFM with or without bFGF 1

week after implantation. (A) Dorsal view of mouse image. The blood flow was measured in boxed area.

(B) The image of laser Doppler perfusion of tissues injected with different gelatin hydrogel granules. (a)

Hydrogels incorporating PGFM and bFGF, (b) PGFM, (c, i) bFGF, (d) PPP or (e) PBS, and (f) non-treatment. (C) The percentage of blood perfusion in the newly formed blood vessels around the tissue 
injected with gelatin hydrogel granules. The percentage of blood perfusion in the right (ischemic) limb was calculated as for that in the left (non-ischemic) limb of the same mouse. The baseline is perfusion index of non-ischemic limb. 


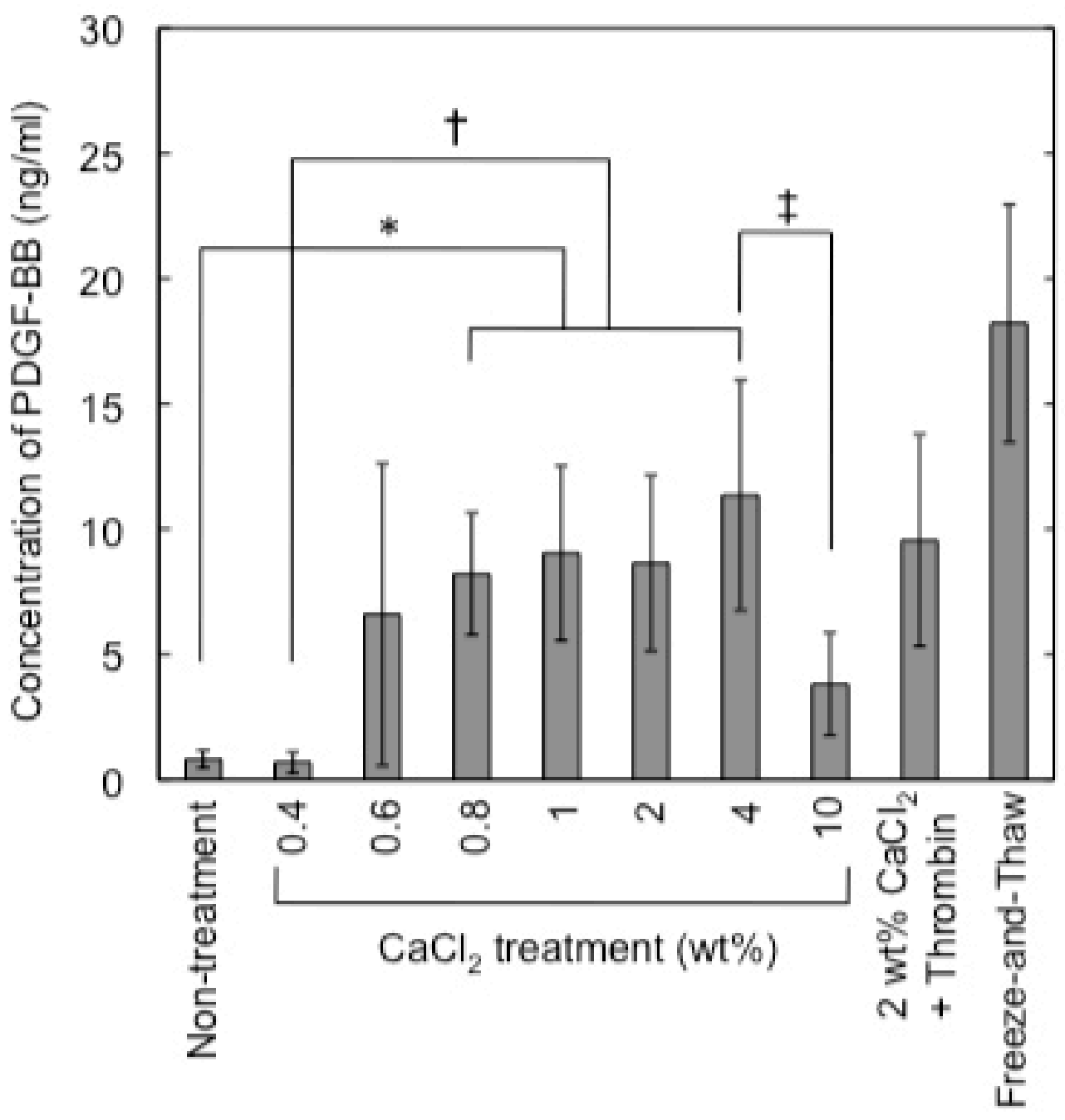




\section{Figure 2}

\section{(A)}

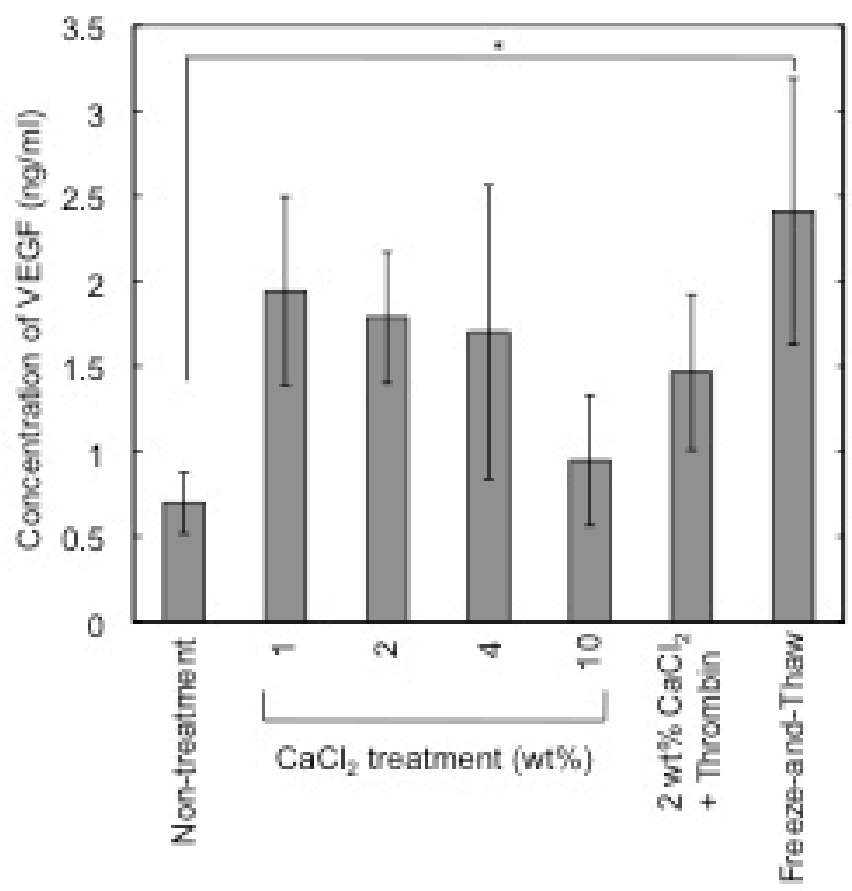

(C)

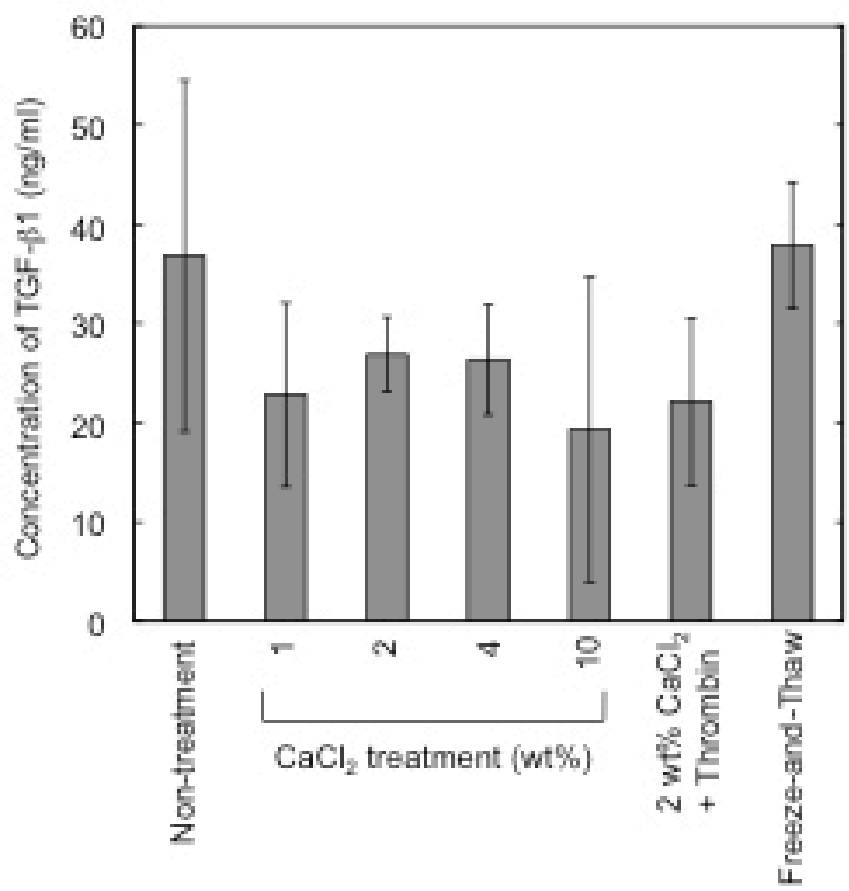

(B)

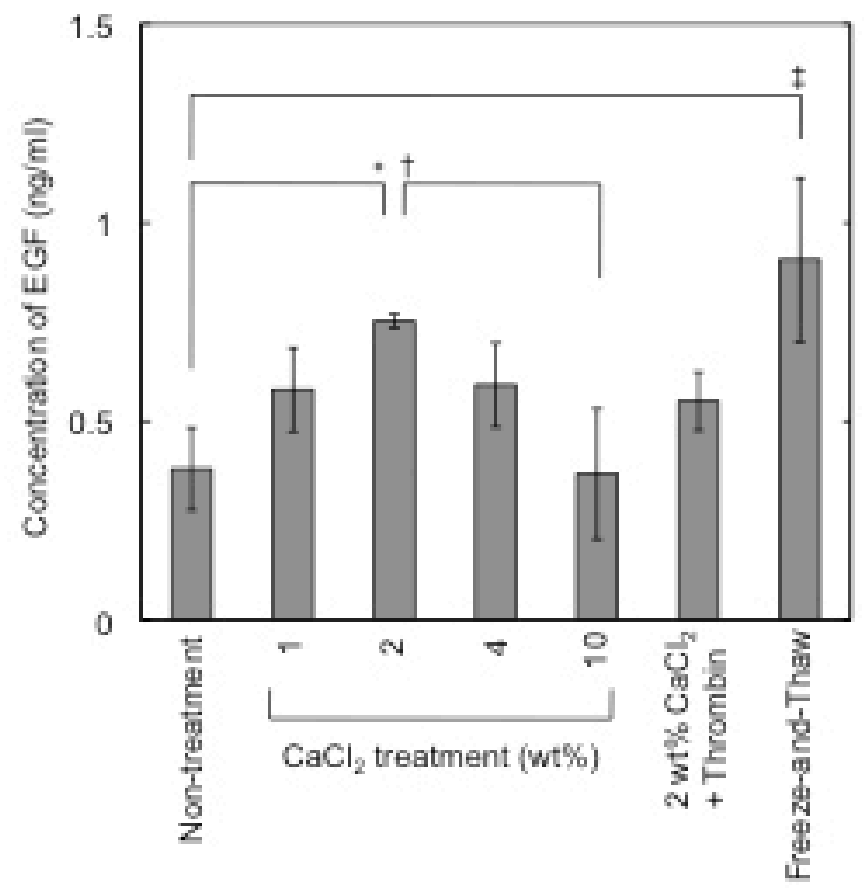


Figure 3

(A)

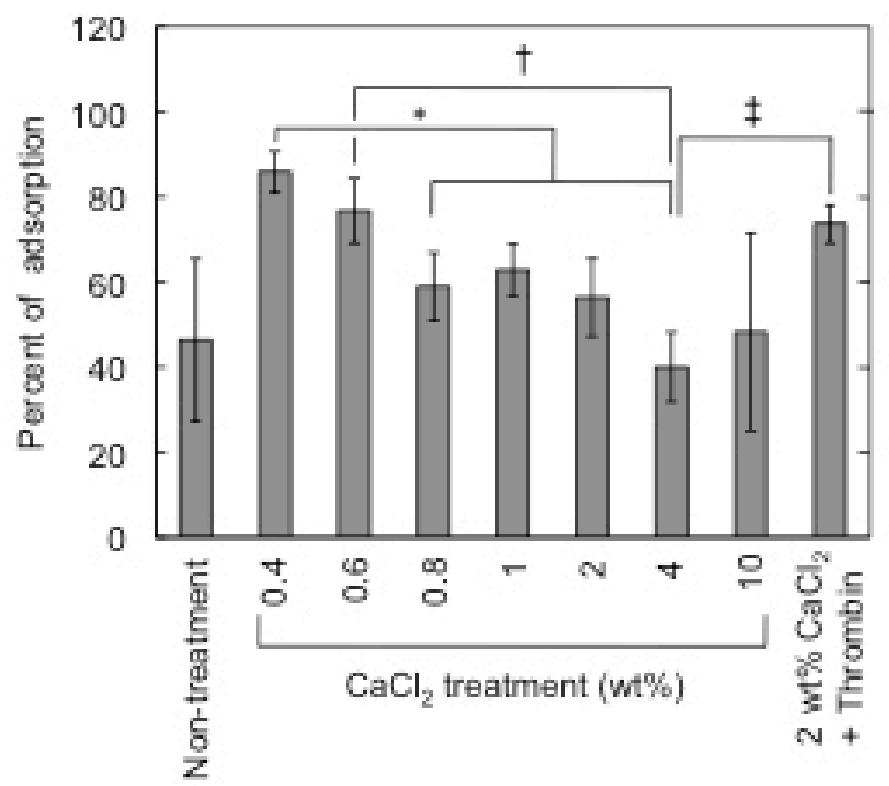

(C)

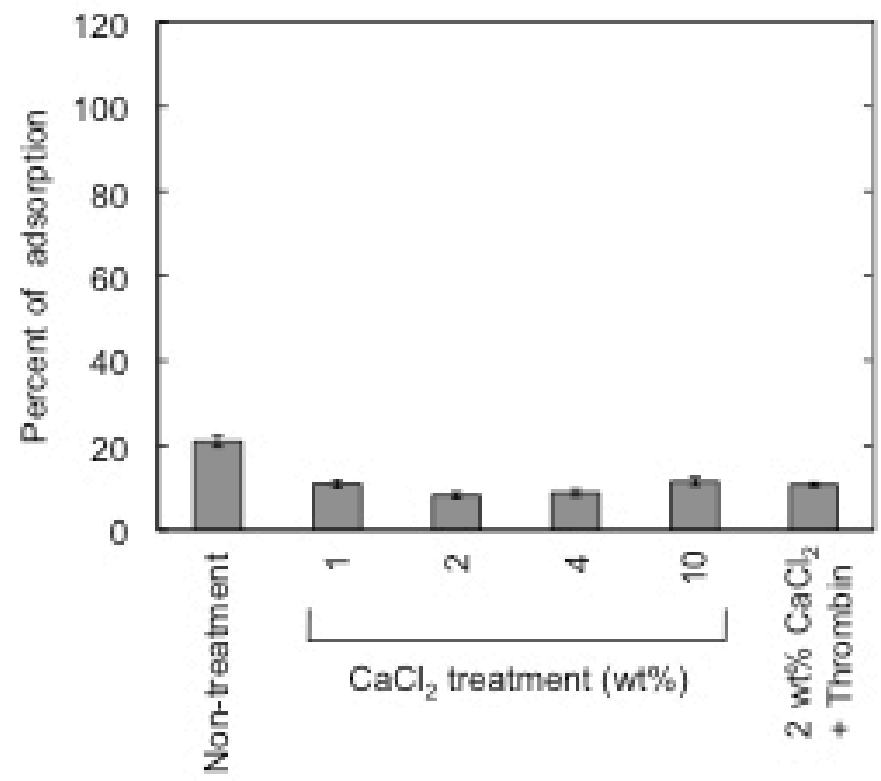

(B)

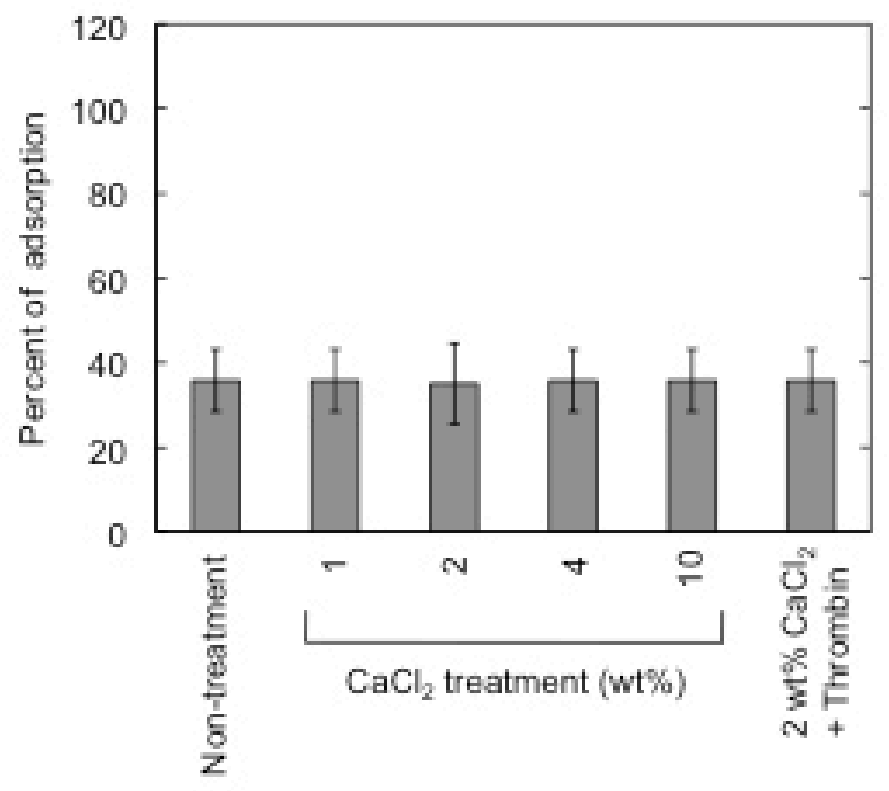

(D)

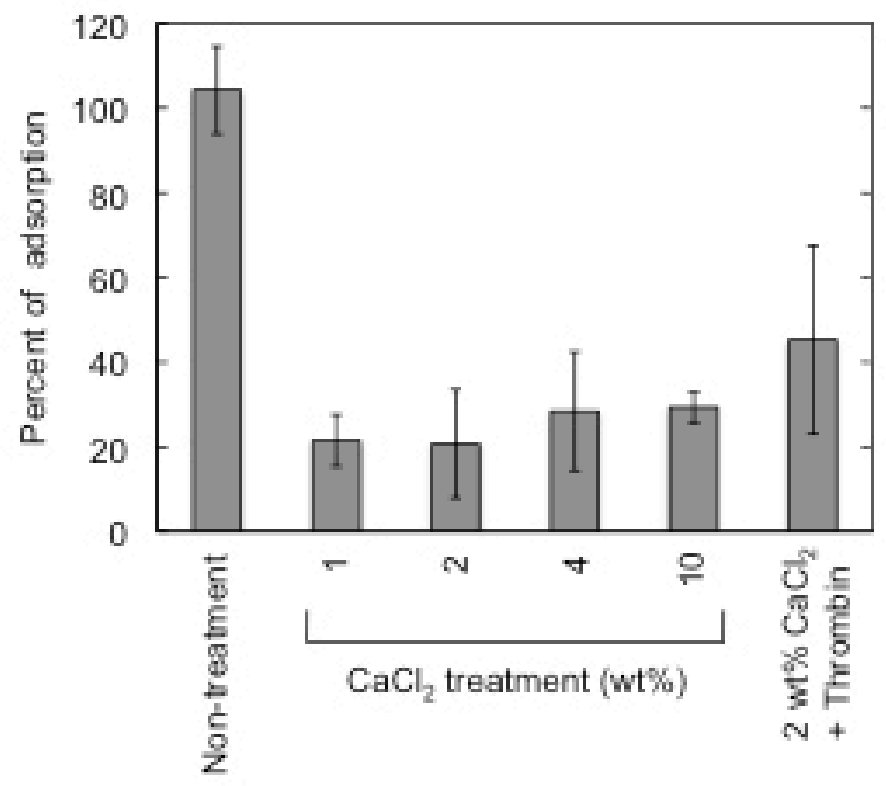




\section{Figure 4}

(A)

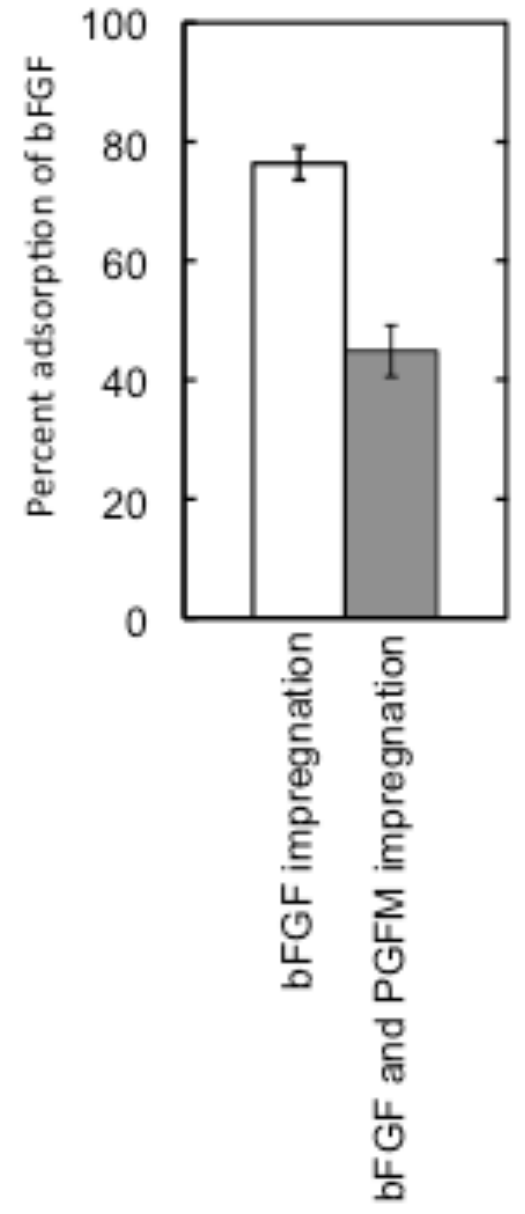

(B)

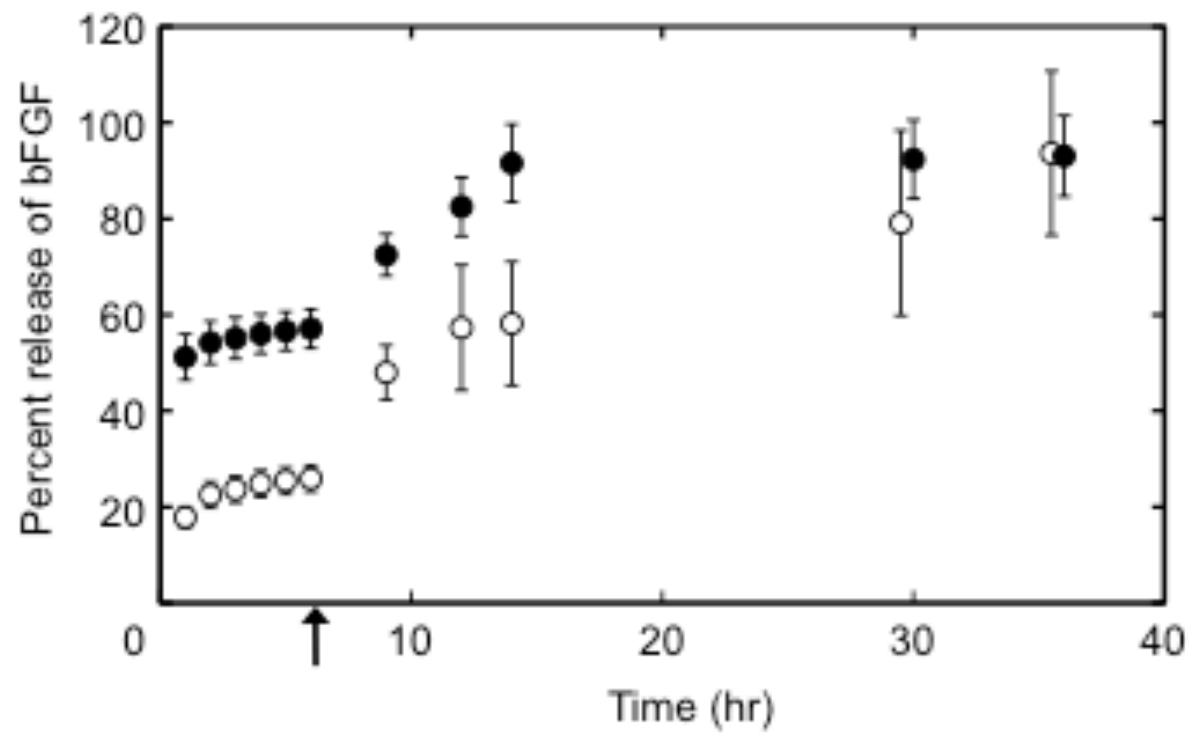




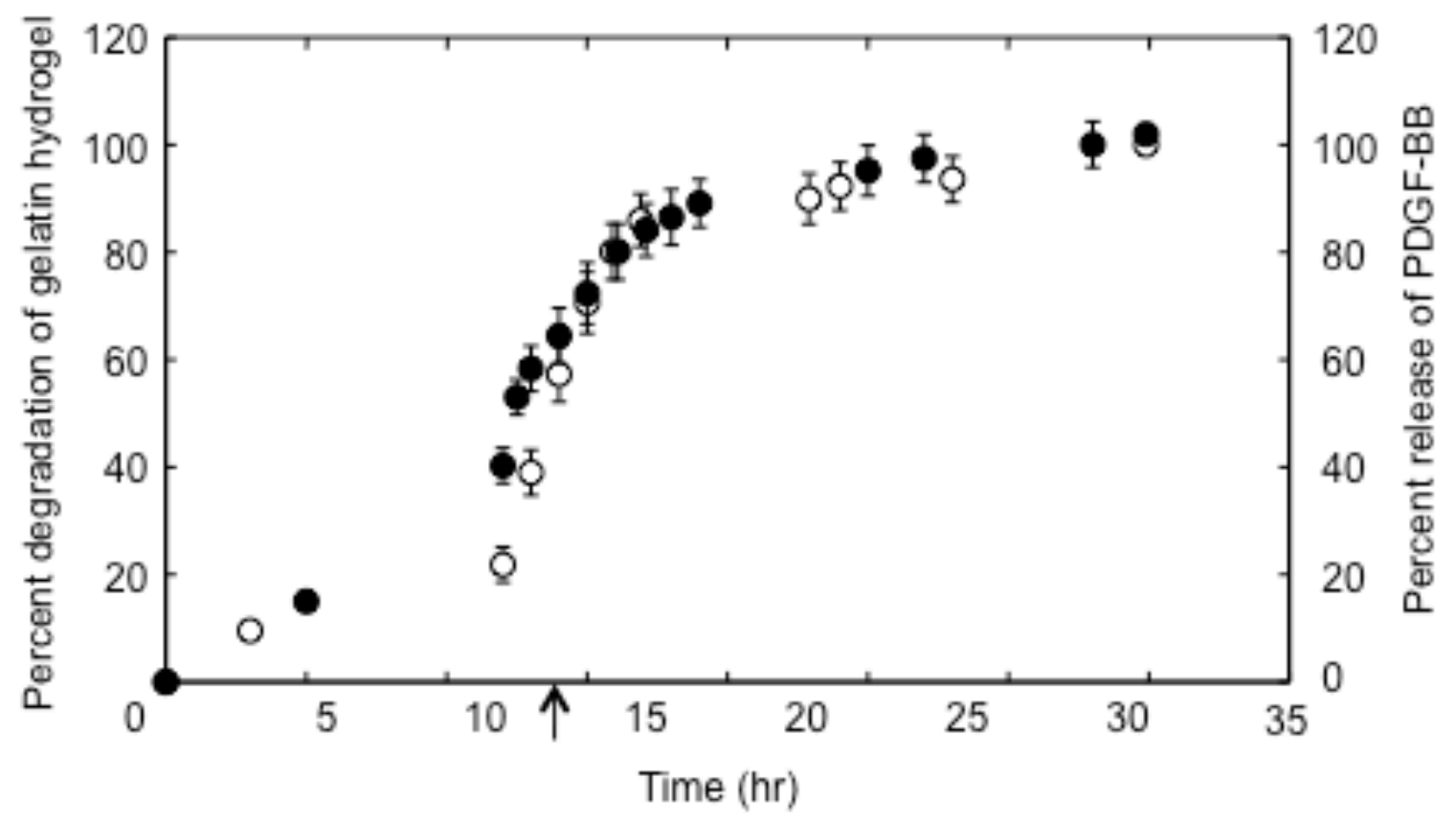


공 京都大学

Figure 6
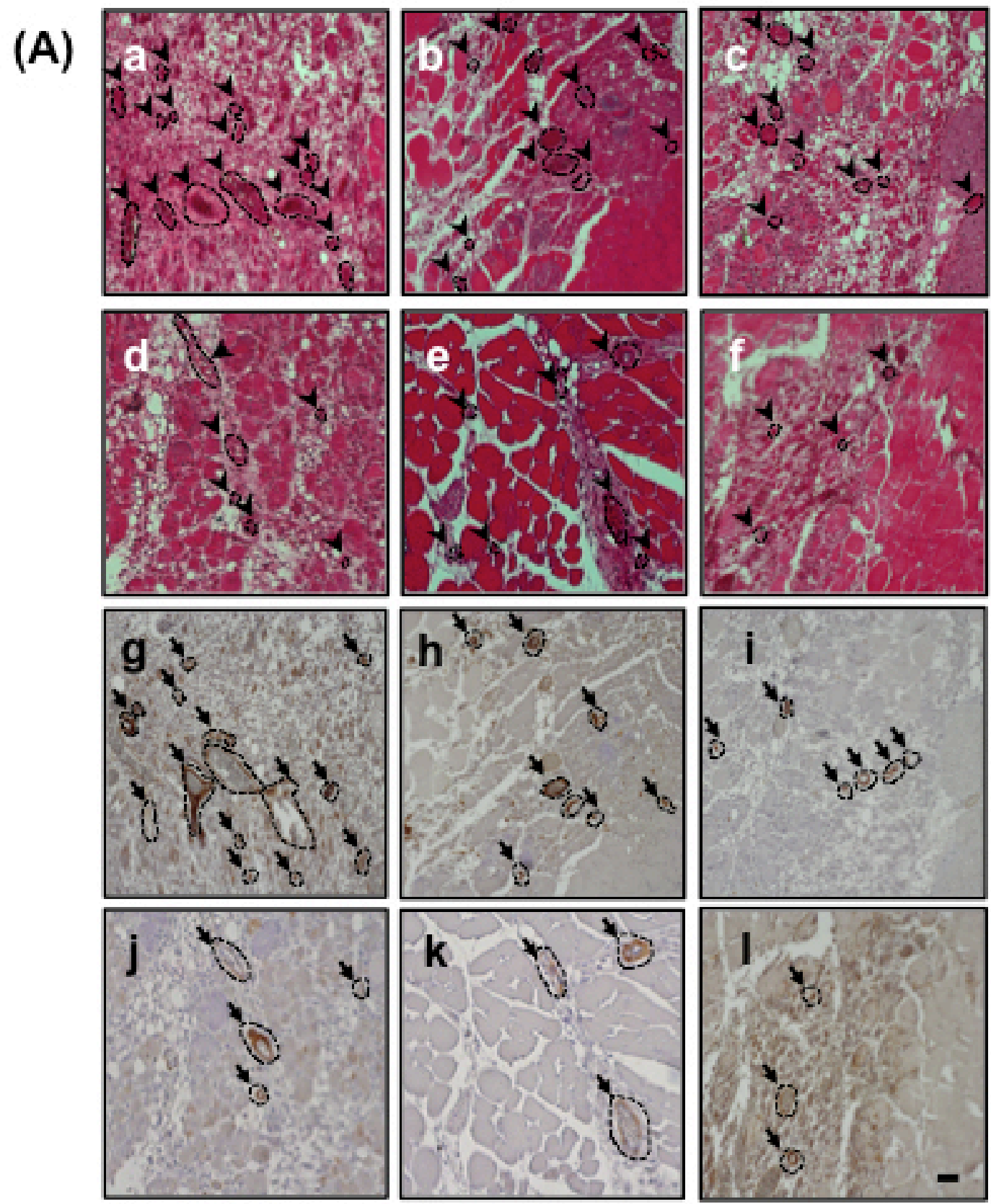
Figure 6

(B)

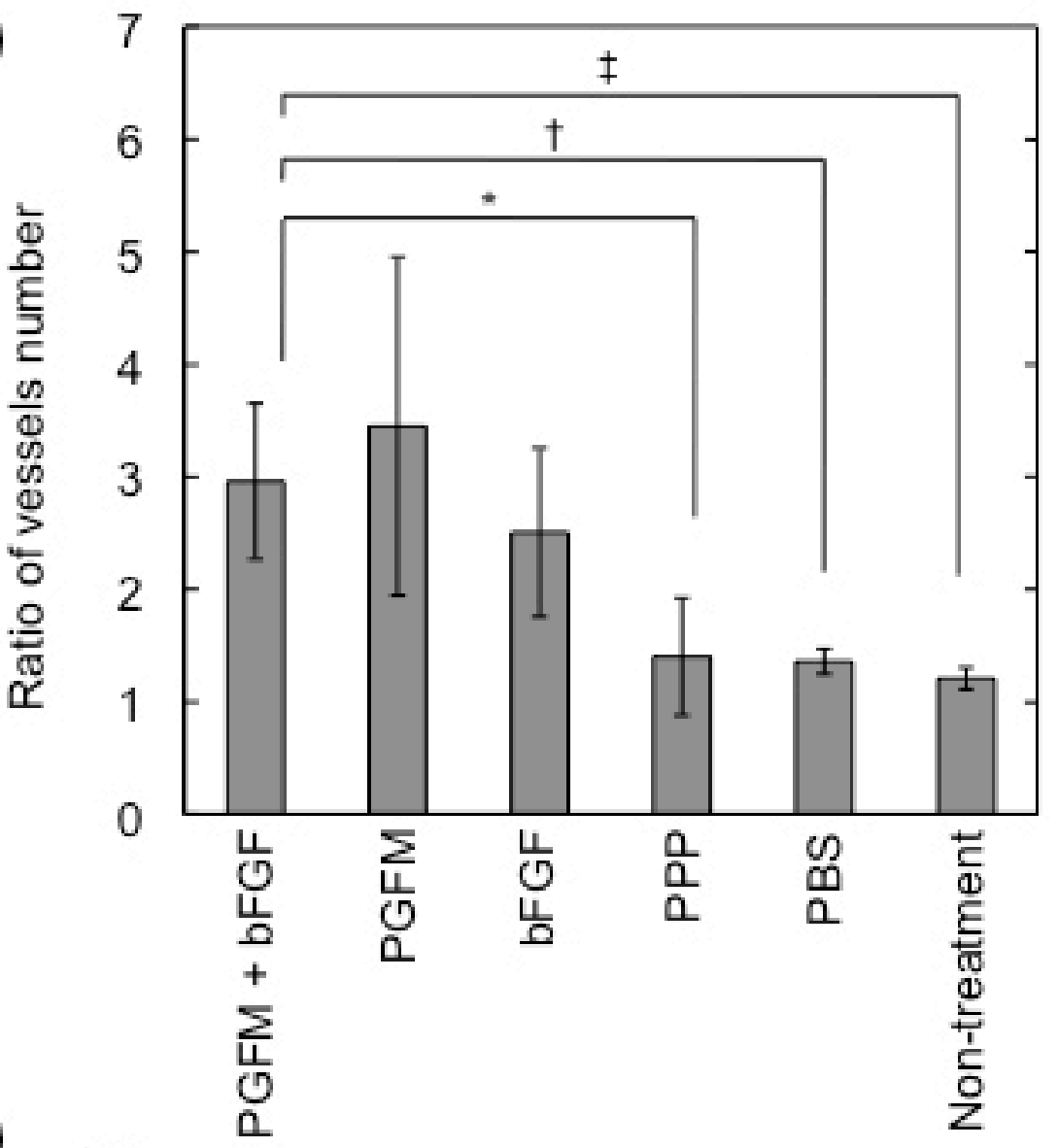

(C)

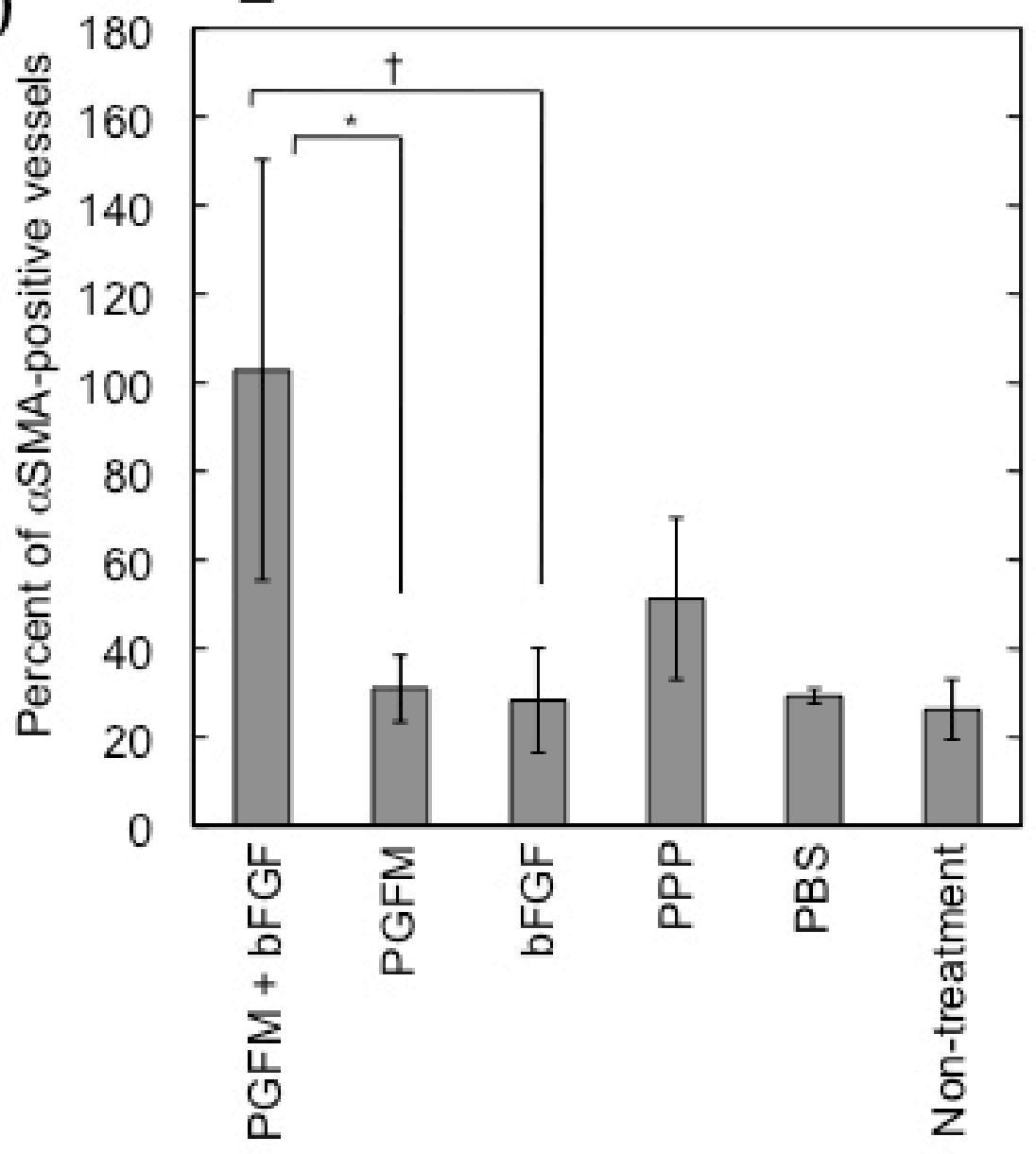




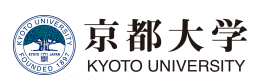

(A)

Figure 7

(B)
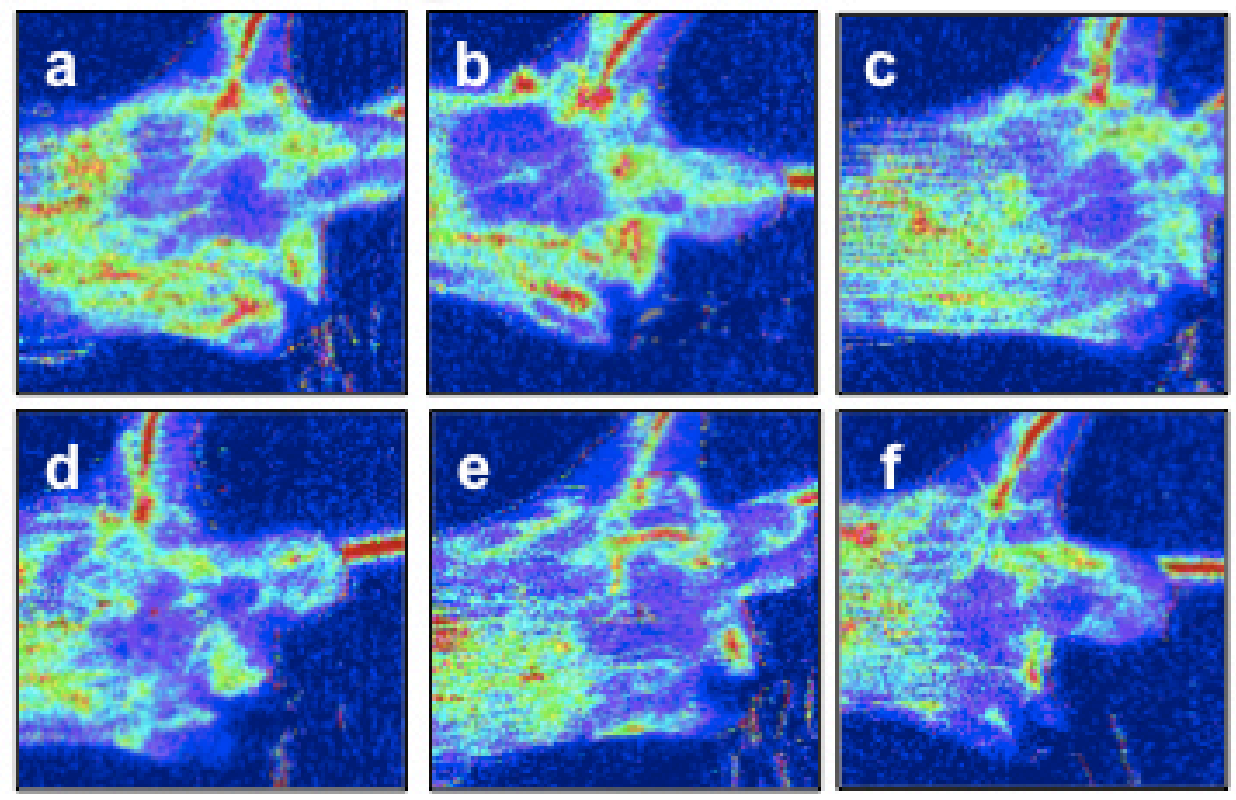

(C)

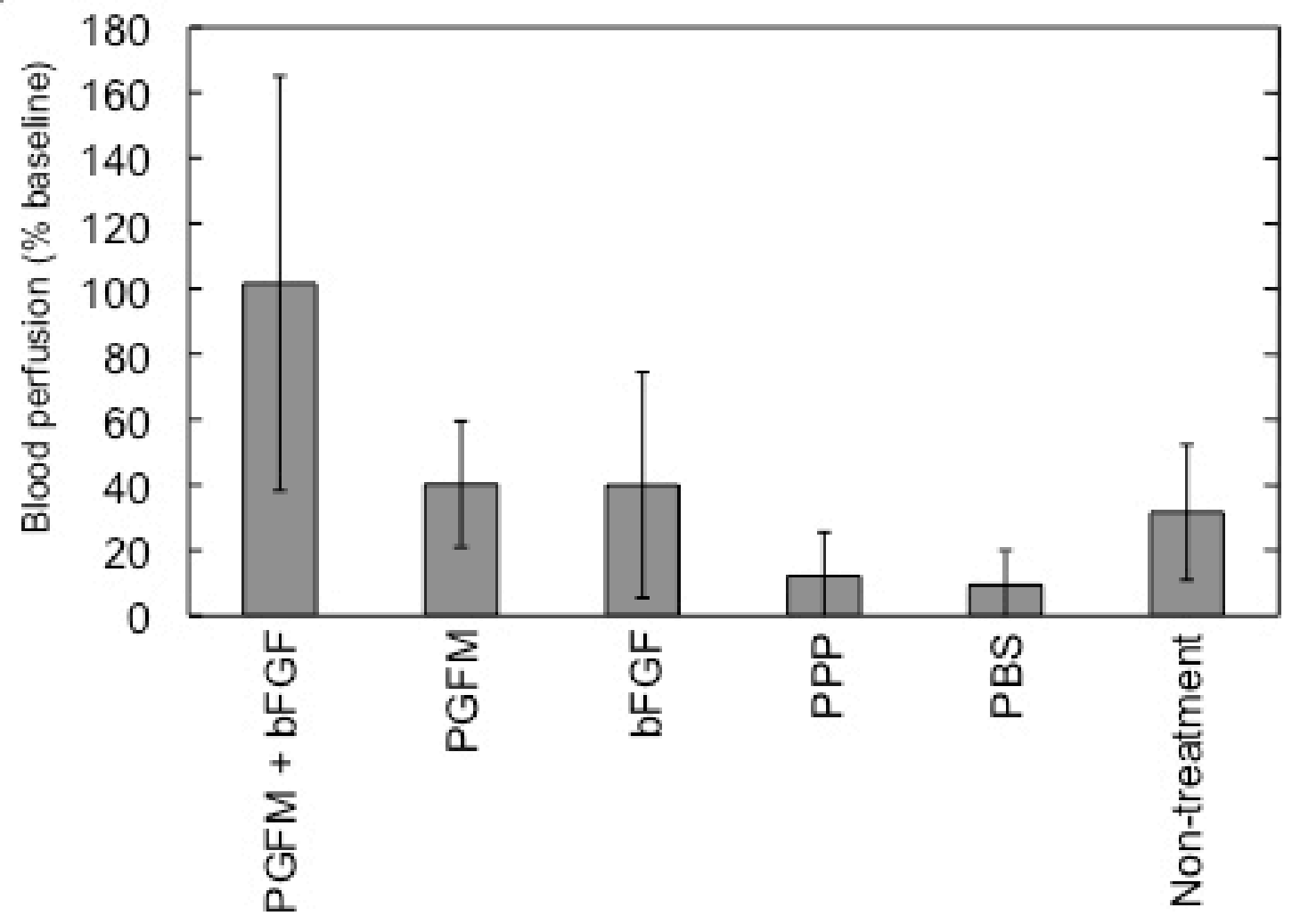


Table 1 Concentration of growth factors in PRP

Growth factor Concentration $(\mathrm{pg} / \mathrm{ml})$

PDGF-BB $9440 \pm 1620$

VEGF

$2040 \pm 971$

TGF- $\beta_{1}$

$30500 \pm 20500$

EGF

$906 \pm 206$

bFGF

$32.6 \pm 8.7$

The growth factors were extracted from PRP through the freeze-and thaw treatment. 